\title{
Mathematical modeling of the outbreak of COVID-19
}

\author{
Arvind Kumar Sinha ${ }^{1} \cdot$ Nishant Namdev ${ }^{1} \cdot$ Pradeep Shende $^{1}$
}

Received: 30 June 2021 / Revised: 20 November 2021 / Accepted: 23 November 2021 / Published online: 10 December 2021

(c) The Author(s), under exclusive licence to Springer-Verlag GmbH Austria, part of Springer Nature 2021

\begin{abstract}
The novel coronavirus SARS-Cov-2 is a pandemic condition and poses a massive menace to health. The governments of different countries and their various prohibitory steps to restrict the virus's expanse have changed individuals' communication processes. Due to physical and financial factors, the population's density is more likely to interact and spread the virus. We establish a mathematical model to present the spread of the COVID-19 in India and worldwide. By the simulation process, we find the infected cases, infected fatality rate, and recovery rate of the COVID-19. We validate the model by the rough set method. In the method, we obtain the accuracy for the infected case is $90.19 \%$, an infection-fatality of COVID-19 is $94 \%$, and the recovery is $85.57 \%$, approximately the same as the actual situation reported WHO. This paper uses the generalized simulation process to predict the outbreak of COVID-19 for different continents. It gives the way of future trends of the COVID-19 outbreak till December 2021 and casts enlightenment about learning the drifts of the outbreak worldwide.
\end{abstract}

Keywords Covid-19 $\cdot$ Epidemiology $\cdot$ Government actions $\cdot$ Public reactions $\cdot$ Rough set $\cdot$ Pandemic

\section{Introduction}

A novel coronavirus outbreak has started on 29 December 2019 in Wuhan (China). Later, it has progressively expanded to the various countries of the world. Based on its dangerous expansion in the world, the WHO declared a Public Health Emergency of International Concern [WHO India Report 1] and pandemic [WHO India Report 7] (Corona virus disease COVID-19 2020). The most common symptoms of COVID19 are fever, dry cough, breathing difficulty, sore throat, or diarrhoea [MoHFW, Government of India 25 March 2020 Awareness materials] (Corona virus disease (COVID-19 INDIA) 2020).

The first coronavirus confirmed case in India was reported on 30 January 2020 in Kerala (India). The patient was a student of Wuhan (China) (Corona virus disease (COVID-19) 2020). Up to 4 March 2020, six confirmed infected cases were reported in India as the classification transmission-imported from abroad. On 5 March 2020, a total of 29 confirmed coronavirus cases by local transmission mode (Corona virus disease (COVID-19) 2020). On

Arvind Kumar Sinha

aksinha.maths@nitrr.ac.in

1 Department of Mathematics, National Institute of Technology Raipur, Raipur, Chhattisgarh 492010, India
13 March 2020, the first death has been reported by coronavirus diseases in India (Corona virus disease (COVID19) 2020; Corona virus disease (COVID-19 INDIA) 2020). The COVID-19 is considered zoonotic starting from bats to intermediate animals to people (Zhou et al. 2020) and is geographically connected with Wuhan's seafood business (Cohen 2020). However, in the Indian scenario, the zoonotic transmission is zero as the cases are only imported from foreign countries. So, only human-to-human transfer of COVID-19 has been established through respiratory droplets (Chan et al. 2020) and asymptomatic infection (Kupferschmidt 2020). India's administration has directed the dissolution of essential functions to prevent coronavirus disease from restraining diseases.

The Janta Curfew has been imposed on 22 March 2020. India's government issued orders for State/UT's prescribing total lockdown for containment of coronavirus disease, epidemic in the nation for 21 days with effect from 25 March 2020. Every incoming foreign flight has ceased from 25 March 2020 to 14 April 2020. Indian Railways issued an order from 22 March 2020 to 14 April 2020 will be treated under "Force Measure." Passenger movement has been restricted, including inter-state travel [WHO India Report 9] (Corona virus disease (COVID-19 INDIA) 2020). The government has released so many advisories as a measure to protect from the coronavirus; among these travel advisories, social distancing, home 
quarantine, and immunity-boosting for self-care are necessary measures for coronavirus crisis (Corona virus disease (COVID-19 INDIA) 2020).

In the model, we follow the pattern of two-sided efforts for analyzing the COVID-19 problem (one side as people of the country and another side as government efforts) (He et al. 2013). Liu et al. 2020 on the transmission of coronavirus in India and worldwide. We assume that if some actions change from both sides, then the model will update. The parameter values may be changed when the situation changes. These are some limitations of the model.

Since the disease transmission rate is uncertain, we develop a mathematical model to present the spread of the COVID19 in India and worldwide. This model is helpful for further modeling studies, and we can compare our model with previous mathematical models (Wu et al. 2020a, b; Modelling study 2020; Mahase 2020; Bekiros and Kouloumpou 2020; Barmparis and Tsironis 2020; Yousefpour et al. 2020; Contreras et al. 2020; Ivorra et al. 2020; Liang 2020; Li et al. 2020; Wu and McGoogan 2020) and with actual data values (MoHFW India) (Corona virus disease (COVID-19) 2020) for the authentication of the model.

\section{Mathematical model}

\subsection{Assumptions}

We take the following assumptions:

1. If people get infected once, they can get infected once again.

2. We consider the situation of complete lockdown and unlocking, with Governmental action and individual reactions.

We propose the following mathematical model of the Covid-19:

$S_{U}$ stands for sensitive people, $I_{N}$ stands for infected people, $R_{E}$ stands for improved individuals, $i_{r}$ stands for epidemic rate, $d_{r}$ stands for loss rate, $r_{r}$ stands for improvement rate, $s_{r}$ stands for improved individuals have lost their immunization and became sensitive to the virus, and $s_{g}$ stands for increase in sensitive individuals. The population has been classified into the categories sensitive, exposed, infected, improved, and asymptomatic (Wu and McGoogan 2020).

We propose the following system of equations:

$$
\left\{\begin{array}{l}
\frac{d S_{U}}{d t}=s_{g}-i_{r} S_{U} I_{N}+s_{r} R_{E}-d_{r} S_{U}-i_{r} R_{E} \\
\frac{d I_{N}}{d t}=i_{r} S_{U} I_{N}-i_{r} I_{N}-d_{r} I_{N} \\
\frac{d R_{E}}{d t}=r_{r} I_{N}-s_{r} R_{E}-d_{r} R_{E} \\
\frac{d E_{P}}{d t}=I_{N}+S_{U} i_{r} \\
\frac{d A_{s}}{d t}=I_{N}+R_{E}
\end{array}\right.
$$

The differential equation for the population $P_{N}$ is obtained by the system (1), and given by

$\frac{d P_{N}}{d t}=\left(s_{g}-i_{r} R_{E}\right)-d_{r}\left(S_{U}+I_{N}+R_{E}\right)$

which is equal to,

$\frac{d P_{N}}{d t}=\left(s_{g}-i_{r} R_{E}\right)-d_{r} P_{N}$

Given an original population density $P_{N_{0}}$, we obtain

$P_{N}(t)=P_{N_{0}} e^{-d_{r} t}+\frac{\left(s_{g}-i_{r} R_{E}\right)}{d_{r}}\left(1-e^{-d_{r} t}\right)$

Therefore, if $t \rightarrow \infty$ then $\frac{\left(s_{g}-i_{r} R_{E}\right)}{d_{r}}$.

The system (1) is known as sensitive-infected-improved model. The system has an equilibrium point $\left(S_{U_{0}}, I_{N_{0}}, R_{E_{0}}\right)$,

$\left(S_{U_{0}}, I_{N_{0}}, R_{E_{0}}\right)=\left(\frac{\left(s_{g}-i_{r} R_{E}\right)}{d_{r}}, 0,0\right)$

The Jacobian matrix $\left(J_{M}\right)$ at an equilibrium is

$J_{M}=\left(\begin{array}{ccc}-d_{r} & -i_{r}\left(\frac{s_{g}-i_{r} R_{E}}{d_{r}}\right) & s_{r} \\ 0 & i_{r}\left(\frac{s_{g}-i_{r} R_{E}}{d_{r}}\right)-\left(r_{r}+d_{r}\right) & 0 \\ 0 & r_{r} & -d_{r}-s_{r}\end{array}\right)$

The characteristic polynomial is

$\left(-d_{r}+\lambda\right)\left(-i_{r}\left(\frac{s_{g}-i_{r} R_{E}}{d_{r}}\right)-\left(r_{r}+d_{r}\right)-\lambda\right)\left(d_{r}+s_{r}+\lambda\right)=0$,

and the eigen values are

$\lambda^{1}=-d_{r}$

$\lambda^{2}=-d_{r}-s$

$\lambda^{3}=-i_{r}\left(\frac{s_{g}-i_{r} R_{E}}{d_{r}}\right)-\left(r_{r}+d_{r}\right)$ 
$i_{r}\left(\frac{s_{g}-i_{r} R_{E}}{d_{r}}\right)<\left(r_{r}+d_{r}\right)$

We infer that to stop the spread of the virus, we must lower the epidemic rate by minimizing communication within sound and infected persons or improving the recovery rate $r_{r}$ by medicines. If Eq. (6) exists, each new infection will go out over time. Otherwise,

$i_{r}\left(\frac{s_{g}-i_{r} R_{E}}{d_{r}}\right)>\left(r_{r}+d_{r}\right)$

the system is unstable.

\subsection{The nonnegativity of the solution of the system}

There is an epidemic that will not die in the population. Moreover, there is an equilibrium point $\left(S_{U}^{*}, I_{N}^{*}, R_{E}^{*}\right)$ with $I_{N}^{*}>0$

$i_{r} S_{U}^{*}=r_{r}+d_{r}$

$R_{E}^{*}=\frac{r_{r}}{d_{r}+s_{r}}$

$\frac{i_{r}}{d_{r}} I_{N}^{*}=\frac{i_{r}\left(\frac{s_{g}-i_{r} R_{E}}{d_{r}}\right)-\left(r_{r}+d_{r}\right)}{r_{r}+d_{r}-\frac{r_{r} s_{r}}{d_{r}+s_{r}}}$

Here,

$r_{r}+d_{r}-\frac{s_{r} r_{r}}{d_{r}+s_{r}}>0$, and, therefore, (7) provides that $I_{N}^{*}$ is positive.

\subsection{The system stability}

We have the system of equations as follows:

$\left\{\begin{array}{l}\frac{d S_{U}}{d t}=s_{g}-i_{r} S_{U} I_{N}+s_{r} R_{E}-d_{r} S_{U}-i_{r} R_{E}=h_{1}(\text { say }) \\ \frac{d I_{N}}{d t}=i_{r} S_{U} I_{N}-i_{r} I_{N}-d_{r} I_{N}=h_{2}(\text { say }) \\ \frac{d R_{E}}{d t}=r_{r} I_{N}-s_{r} R_{E}-d_{r} R_{E}=h_{3}(\text { say })\end{array}\right.$

To analyze the stability of equilibria in the model, we adopted the Jacobian matrix $J_{C}$

$J_{C}=\left(\begin{array}{lll}\frac{\partial h_{1}}{\partial S_{U}} & \frac{\partial h_{1}}{\partial I_{N}} & \frac{\partial h_{1}}{\partial R_{E}} \\ \frac{\partial h_{2}}{\partial S_{U}} & \frac{\partial h_{2}}{\partial I_{N}} & \frac{\partial h_{2}}{\partial R_{E}} \\ \frac{\partial h_{3}}{\partial S_{U}} & \frac{\partial h_{3}}{\partial I_{N}} & \frac{\partial h_{3}}{\partial R_{E}}\end{array}\right)$, where

$\frac{\partial h_{1}}{\partial S_{U}}=-i_{r} I_{N}^{*}-d_{r}, \frac{\partial h_{1}}{\partial I_{N}}=-i_{r} S_{U}^{*}, \frac{\partial h_{1}}{\partial R_{E}}=s_{r}-i_{r}$.

$\frac{\partial h_{2}}{\partial S_{U}}=i_{r} I_{N}^{*}, \frac{\partial h_{2}}{\partial I_{N}}=i_{r} S_{U}^{*}-\left(r_{r}+d_{r}\right) \frac{\partial h_{2}}{\partial R_{E}}=0$.

$\frac{\partial h_{3}}{\partial S_{U}}=0, \frac{\partial h_{3}}{\partial I_{N}}=r_{r}, \frac{\partial h_{3}}{\partial R_{E}}=-\left(d_{r}+s_{r}\right)$.

Therefore,

$J_{C}=\left(\begin{array}{ccc}-i_{r} I_{N}^{*}-d_{r} & -i_{r} S_{U}^{*} & s_{r}-i_{r} \\ i_{r} I_{N}^{*} & i_{r} S_{U}^{*}-\left(r_{r}+d_{r}\right) & 0 \\ 0 & r_{r} & -\left(d_{r}+s_{r}\right)\end{array}\right)$

Hence, the characteristic polynomial is

$\operatorname{det}\left(J_{C}-\lambda I\right)=\left(\begin{array}{ccc}-i_{r} I_{N}^{*}-d_{r}-\lambda & -\left(r_{r}+d_{r}\right) & s_{r}-i_{r} \\ i_{r} I_{N}^{*} & -\lambda & 0 \\ 0 & r_{r} & -\left(d_{r}+s_{r}\right)-\lambda\end{array}\right)=0$

That gives

$\left(i_{r} I_{N}^{*}+d_{r}+\lambda\right)\left[\lambda^{2}+\lambda\left(d_{r}+s_{r}\right)\right]+i_{r} I_{N}^{*}$

$\left[\left(r_{r}+d_{r}\right)\left(d_{r}+s_{r}+\lambda\right)-r_{r}\left(s_{r}-i_{r}\right)\right]=0$

We obtain the characteristic equation

$\lambda^{3}+\lambda^{2}\left[\left(i_{r} I_{N}^{*}+d_{r}\right)+\left(d_{r}+s_{r}\right)\right]+\lambda\left[\left(i_{r} I_{N}^{*}+d_{r}\right)\left(d_{r}+s_{r}\right)\right.$

$\left.+i_{r} I_{N}^{*}\left(r_{r}+d_{r}\right)\right]+i_{r} I_{N}^{*}\left[\left(r_{r}+d_{r}\right)\left(d_{r}+s_{r}\right)-r_{r}\left(s_{r}-i_{r}\right)\right]=0$

where

$\delta_{1}=\left(i_{r} I_{N}^{*}+d_{r}\right)+\left(d_{r}+s_{r}\right)$

$\delta_{2}=\left(i_{r} I_{N}^{*}+d_{r}\right)\left(d_{r}+s_{r}\right)+i_{r} I_{N}^{*}\left(r_{r}+d_{r}\right)$

$\delta_{3}=i_{r} I_{N}^{*}\left[\left(r_{r}+d_{r}\right)\left(d_{r}+s_{r}\right)-r_{r}\left(s_{r}-i_{r}\right)\right]$

If at least one root is positive, then the system will be unstable. Otherwise, if all the roots of the equation are negative, then the system will be stable.

\subsection{The Routh-Hurwitz criterion}

The Routh-Hurwitz test was employed as follows in the equation to assure that all roots in the equation were negative while the resulting stipulation was met:

$\delta_{1} \delta_{2}>\delta_{3}$

$\left[\left(i_{r} I_{N}^{*}+d_{r}\right)+\left(d_{r}+s_{r}\right)\right]\left[\left(i_{r} I_{N}^{*}+d_{r}\right)\left(d_{r}+s_{r}\right)+i_{r} I_{N}^{*}\left(r_{r}+d_{r}\right)\right]$

$>i_{r} I_{N}^{*}\left[\left(r_{r}+d_{r}\right)\left(d_{r}+s_{r}\right)-r_{r}\left(s_{r}-i_{r}\right)\right]$

Therefore, by the Routh-Hurwitz test, the model is stable. 


\section{Simulation of the model}

We consider the impact of regulatory effort commences on 23 March 2020. The emigration from Delhi (Capital of India) commences on 31 March 2020 and finishes on 10 April 2020. In this COVID-19, it looks children are saved. Just $0.9 \%$ of the problems are from age fifteen or less (Chou and Friedman 2016), while in India, zero to fourteen years are 5\%. To know this impact, we believe ten percentage of the population is 'protected'. New investigations explained that the interval of COVID-19 could be 5 days (Guan et al. 2020) (Nishiura et al. 2020a), and the median incubation period could be 4 days (Chou and Friedman 2016). These properties suggest a small inactive period and a contagious period.

Therefore, assume a comparatively more modest standard inactive time ( 3 days) and the typical contagious time (4 days). We utilize critical problems and death in the standard response role instead of losses alone. We also enhance the regulatory action's strength so that the model outcomes regularly meet the observation reporting ratio. Specifically, a proportion of the model generated cases will be summarized in facts. Many evidence and studies (Nishiura et al. 2020b; Tuite and Fisman 2020; Zhao et al. 2020a; January 2020) propose that the reporting proportion is time-varying. We summarize the parameters in Table 1. We highlighted this situation as we understand that the individual response and regulatory action were performed in the early epidemic and pandemic (He et al. 2013).

In India's context, we have taken 145 days scenario from 30 January 2020 to 25 June 2020 . We have shown the actual daily and cumulative infected, death, and cured cases in Figs. 1, 2, 3 of 30 January 2020 to 25 June 2020. We have compared the actual daily infected, death, and cured cases with the simulation data of daily infected, death, and cured cases in Figs. 4, 5, 6,

Table 1 Parameters values used in the model

\begin{tabular}{lllll}
\hline S. No & Parameters & Notation & Value or range & Remark \\
\hline 1 & Infected rate & $i_{r}$ & $\{1000,10,000\}(\text { day })^{-1}$ & Stepwise function \\
2 & Total initial population & $P_{N_{0}}$ & 1.30 billion & Constant \\
3 & Initial Susceptible population & $S_{u}$ & $0.9 P_{N_{0}}$ & Constant \\
4 & Proportion of severe cases & $d_{r}$ & 3 per 100 & Constant \\
\hline
\end{tabular}

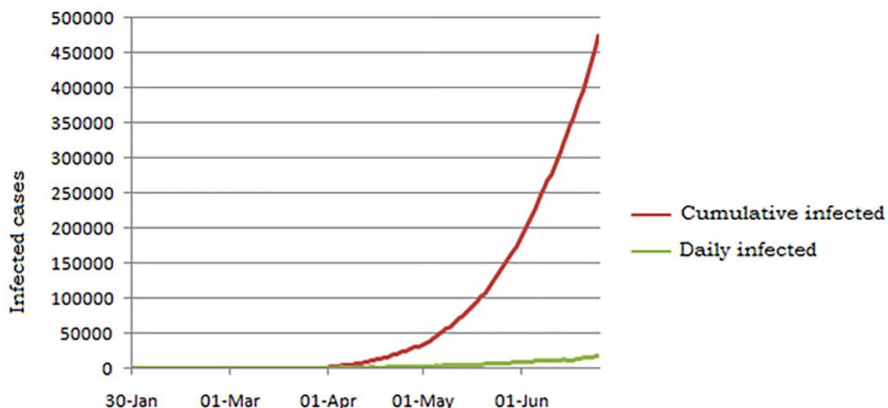

(a)

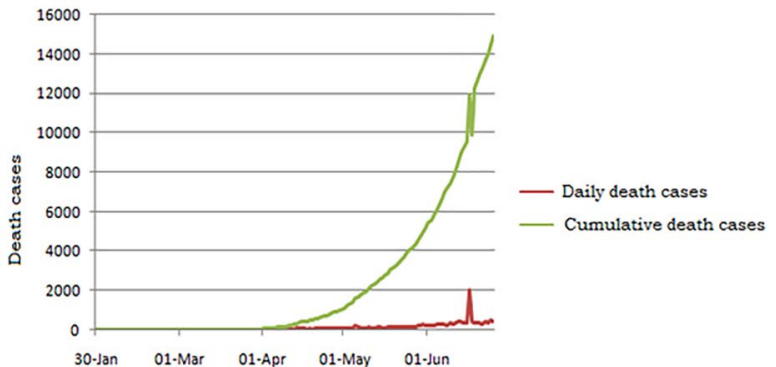

(b)

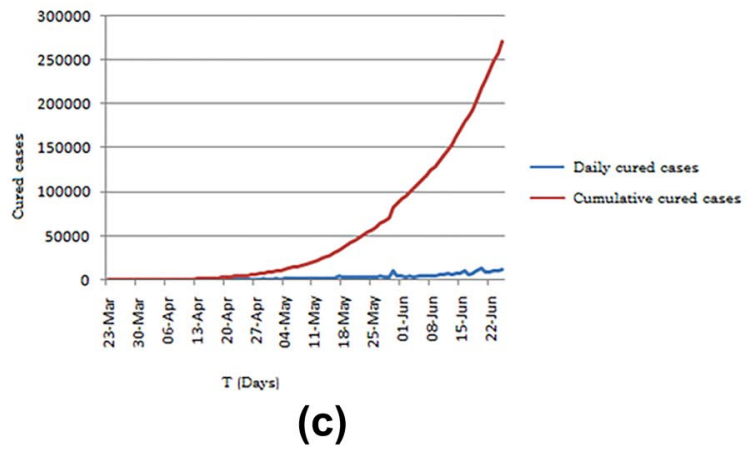

Fig. 1 a The total number of actual cumulative and daily infected cases per day in India until 25 June 2020. b The total number of actual cumulative and daily death cases per day in India till 25 June
2020. c The total number of actual cumulative and daily cured cases per day in India till 25 June 2020 


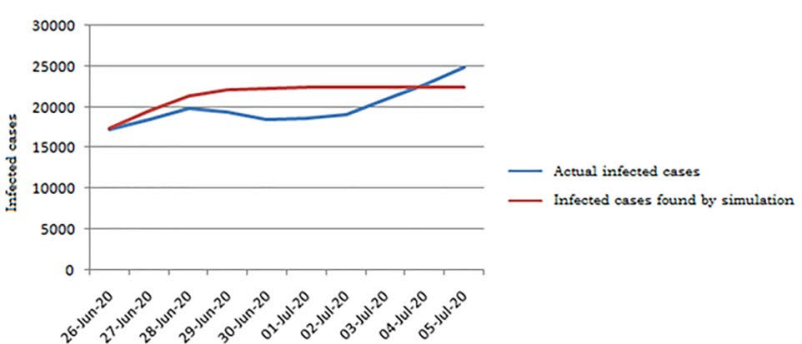

(a)

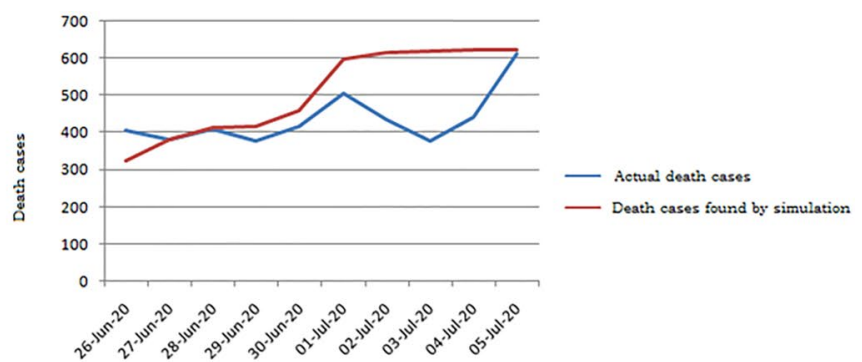

(b)

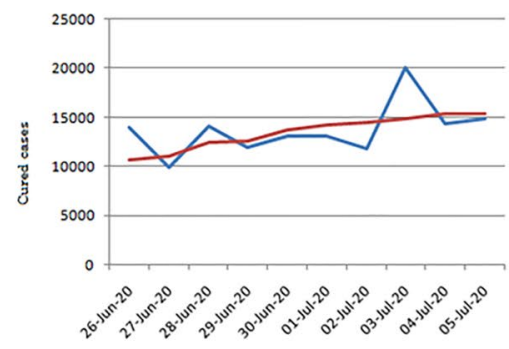
- Cured cases found by simulation

(c)

Fig. 2 a The comparison between actual infected cases and the numbers of infected cases found by simulation for India from 26 June 2020 to 05 July 2020. b The comparison between actual death cases and the number of death cases found by simulation for India from 26

June 2020 to 05 July 2020. c The comparison between actual cured cases and the number cured cases found by simulation for India from 26 June 2020 to 05 July 2020

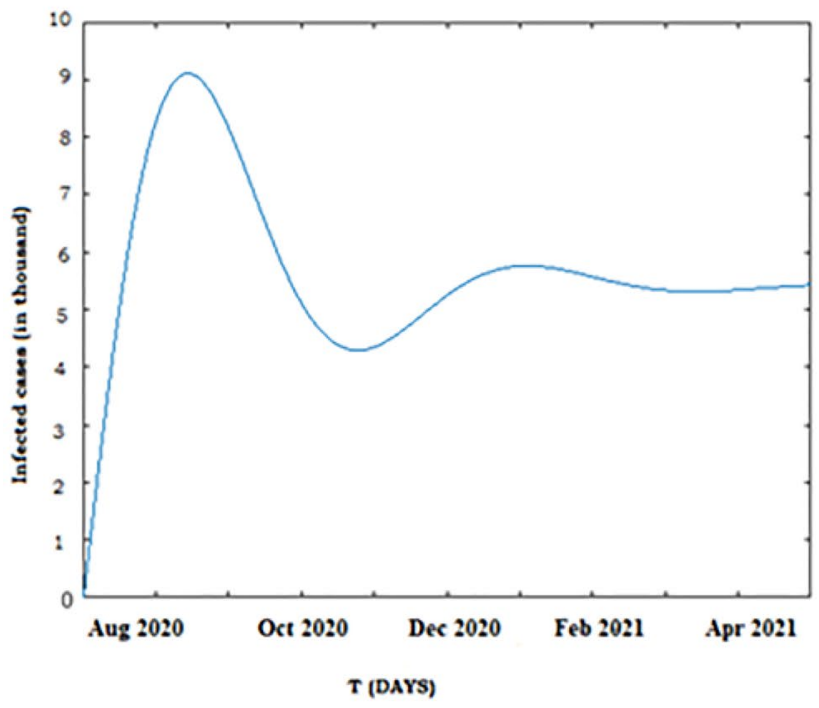

(a)

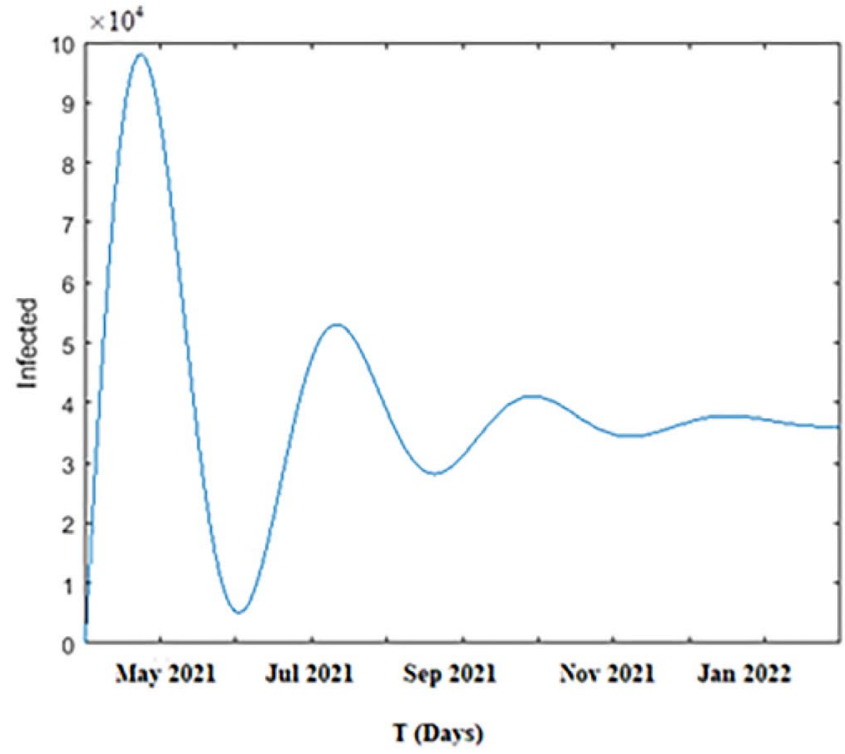

(b)

Fig. 3 a, b The number of infected cases per day predicted by simulation for India from 6 July 2020 to Jan 2022

respectively, from 26 June 2020 to 05 July 2020 . We have also predicted the daily infected, death, and cured cases in Figs. 7, 8, 9, respectively, from 06 July 2020 to 31 December 2021. Table 2 compares of infected, death, and cured cases found by the simulation process with actual data.

\section{Results and analysis of the model}

\subsection{Training}

For training, we have taken data from 30 January 2020 to 25 June 2020 (Corona virus disease (COVID-19 INDIA) 


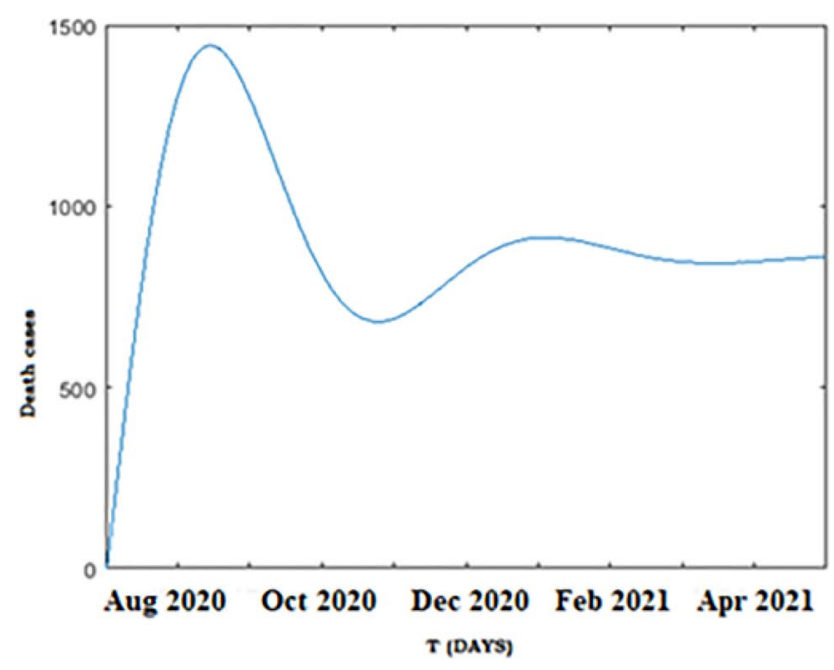

(a)

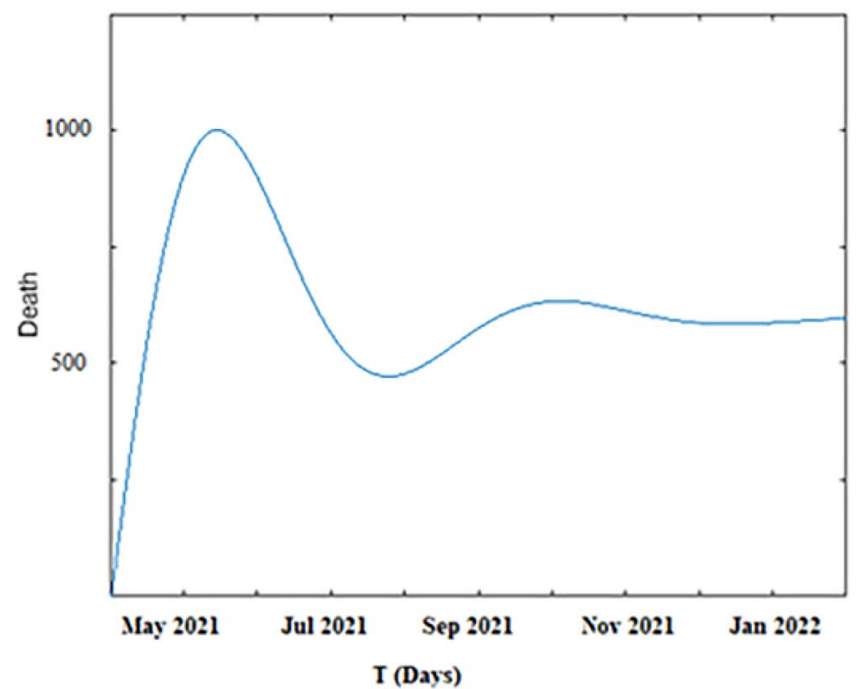

(b)

Fig. 4 a, b The number of death cases per day predicted by simulation for India from 6 July 2020 to Jan 2022

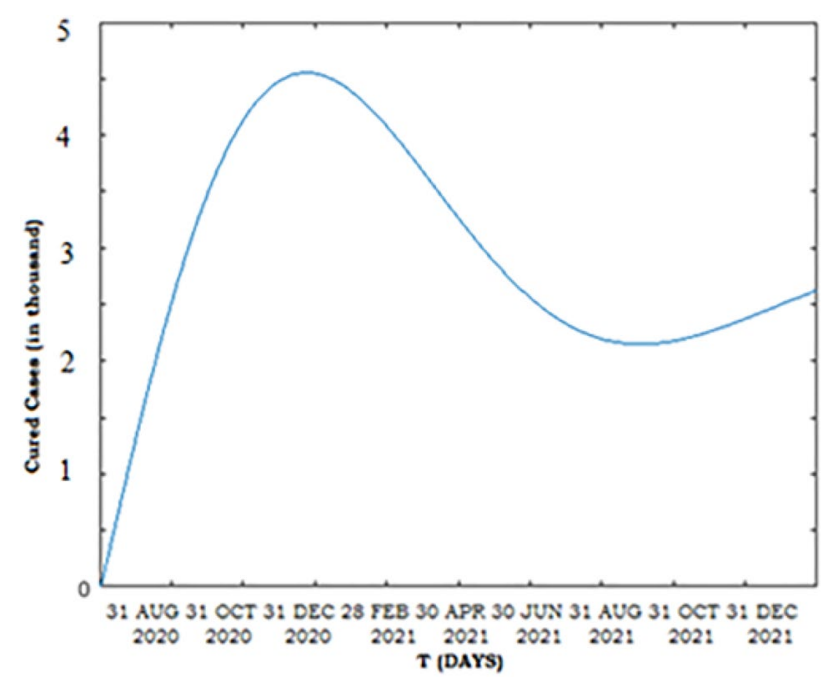

Fig. 5 The number of cured cases per day predicted by simulation for India from 6 July 2020 to Jan 2022

2020), and we found the actual daily and cumulative data for the infected, dead, and cured cases. The total number of actual daily and cumulative infected cases until 25 June 2020 is shown in Fig. 1a, the total actual daily and cumulative death rates till 25 June 2020 are in Fig. 1b, and the total actual daily and cumulative cured/recovered cases until 25 June 2020 are in Fig. 1c. In India's context, for training, we have shown simulated data in Table 2 from 26 June 2020 to 05 July 2020 with the comparison with actual data (Corona virus disease (COVID-19 INDIA) 2020), and we have shown simulated curves for infected, death, and cured cases in Fig. 2a-c.

\subsection{Testing}

By testing, we found that the number of cumulative infected cases in India was 562 by 25 March 2020, and the number of daily real infected cases in India was 24,850 by 05 July 2020 , which is approximately in line with the simulation process (i.e., 22,414) (Table 2). Likewise, the number of cumulative death cases in India was nine by 25 March 2020, and the number of daily death cases in India was 613 by 05 July 2020, which is approximately in line with the simulation process (i.e., 624) (Table 2). In the same way, we have also found that the number of cumulative cured cases in India was 45 by 25 March 2020, and the number of daily cured cases in India was 14,856 by 05 July 2020 , which is approximately in line with the simulation process (i.e., 15,369) (Table 2).

We also found the cumulative infected cases were 687,959 by the simulation process close to the cases (i.e., 648,315 actual cases) reported by the Government of India (Corona virus disease (COVID-19) 2020; Corona virus disease (COVID-19 INDIA) 2020) to WHO till 05 July 2020. By simulation data, we found that the rate of infected cases against the total population to be $0.05 \%$ ( $0.04 \%$ reported by the Government of India (Corona virus disease (COVID-19 INDIA) 2020)) in India's context. The death cases were 19,976 by the simulation close to cases (i.e., 18,655 actual cases) reported (Corona virus disease (COVID-19) 2020; Corona virus disease (COVID19 INDIA) 2020) to WHO till 05 July 2020. With this simulation data of infected and death cases, we found an infection-fatality rate of COVID-19 to be $2.90 \%(2.82 \%$ reported by the Government of India (Corona virus disease 


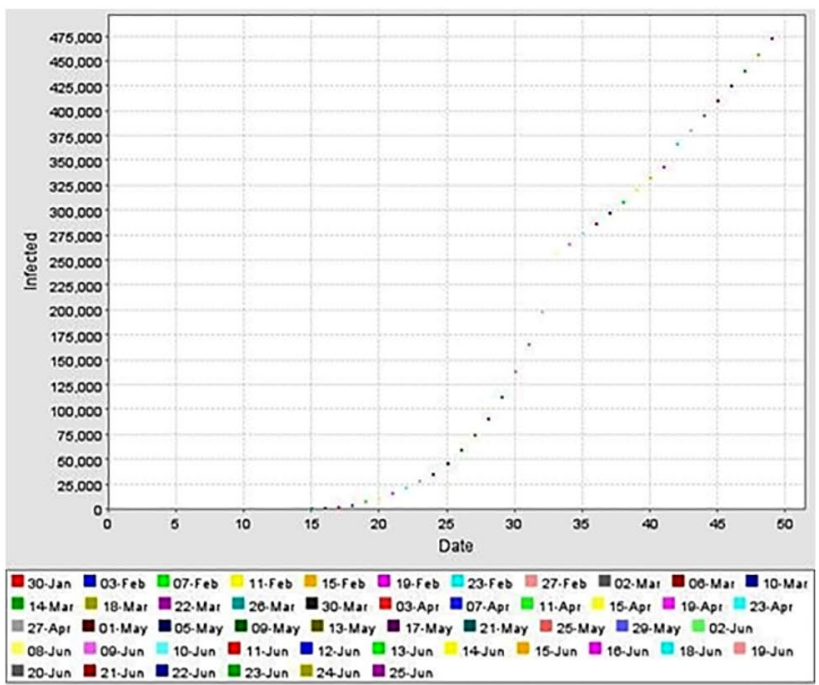

(a)

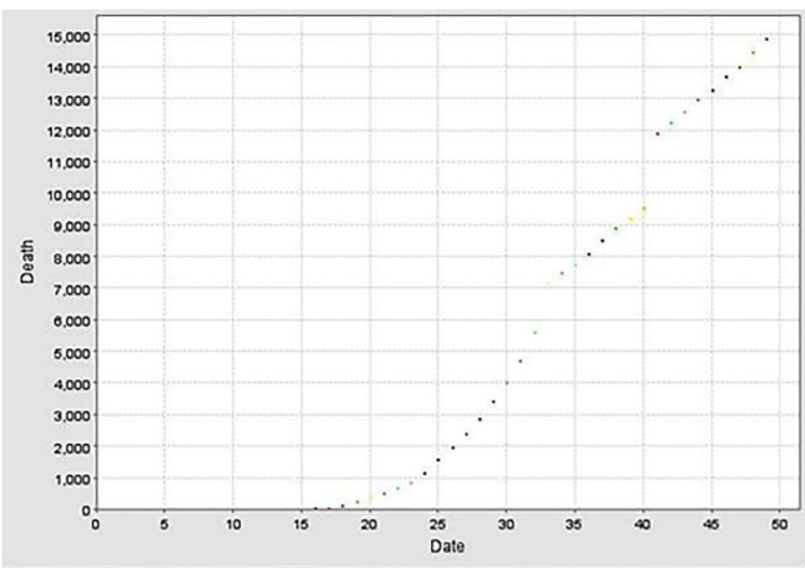

Q

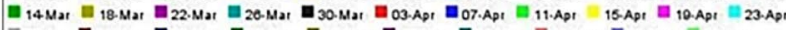

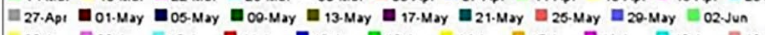

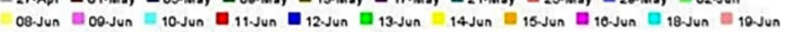

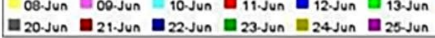

(b)

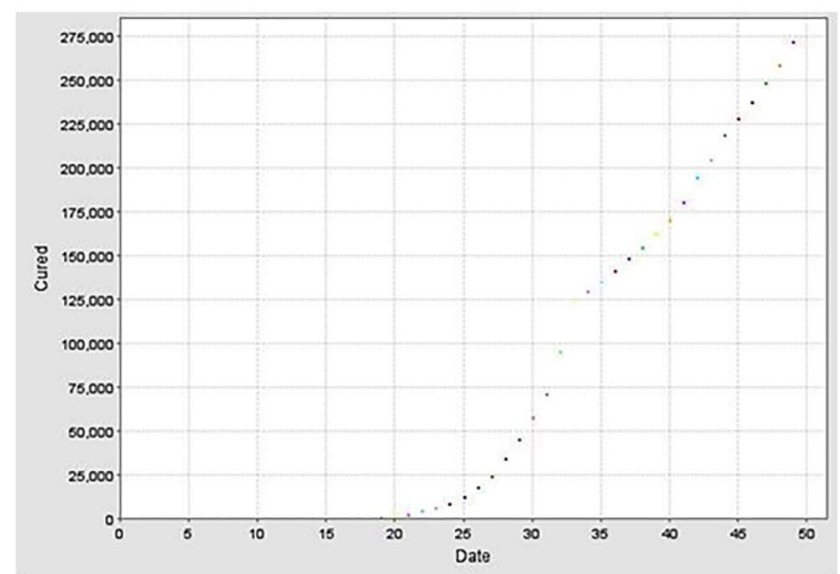

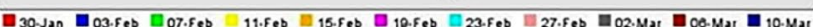

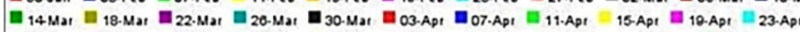

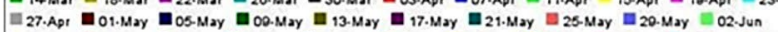

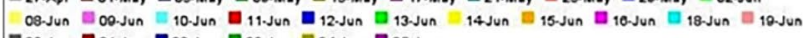

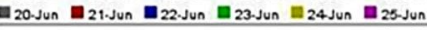

(c)

Fig. 6 a The total number of cumulative infected cases in India until 25 June 2020 . b The total number of cumulative death cases in India until 25 June 2020. $\mathbf{c}$ The total number of cumulative cured cases in India until 25 June 2020

(COVID-19 INDIA) 2020)) in India's context. Similarly, the cured cases were 406,284 till 05 July 2020 by the simulation process. The recovery rate is $59.05 \%(60.77 \%$ reported by the Government of India Corona virus disease (COVID-19 INDIA) 2020 in India's context by simulation data of infected and cured cases. So, the infected, death, and recovery rates found by the simulation are approximately the same as the data provided by the WHO India report and MoHFW India (Corona virus disease (COVID19) 2020; Corona virus disease (COVID-19 INDIA) 2020).

Therefore, the infected case's accuracy is $90.19 \%$, an infection-fatality of COVID-19 is approximately $94 \%$, and the recovery is $85.57 \%$.

\subsection{Prediction for infected, death, and cured cases in Indian Scenario}

We review the regularly published data from India (Corona virus disease (COVID-19 INDIA) 2020). There is an advancing inclination of everyday new evidence and losses. We show that those data obtained massively affected via the availability of medicinal stocks and wellness concern operators. We see a lag of fourteen days in sign start and lab certification of COVID-19. We consider a proportion of everyday occurrences would be informed subsequent fourteen days after infectiousness start. Based 


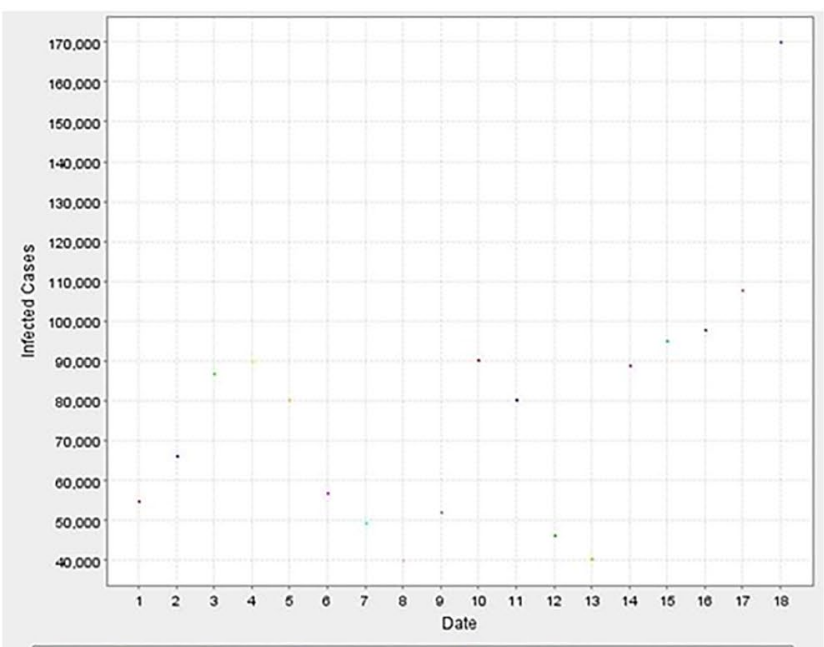

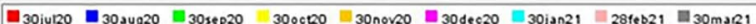

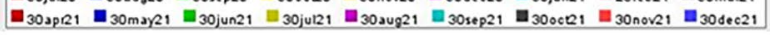

(a)

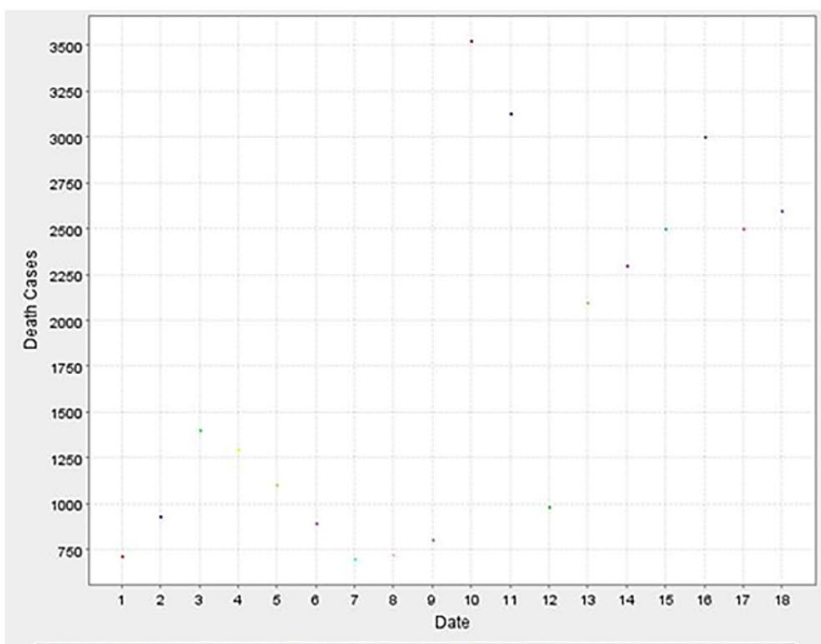

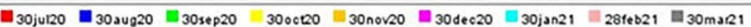

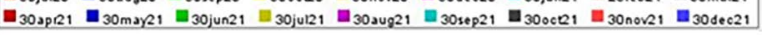

(b)

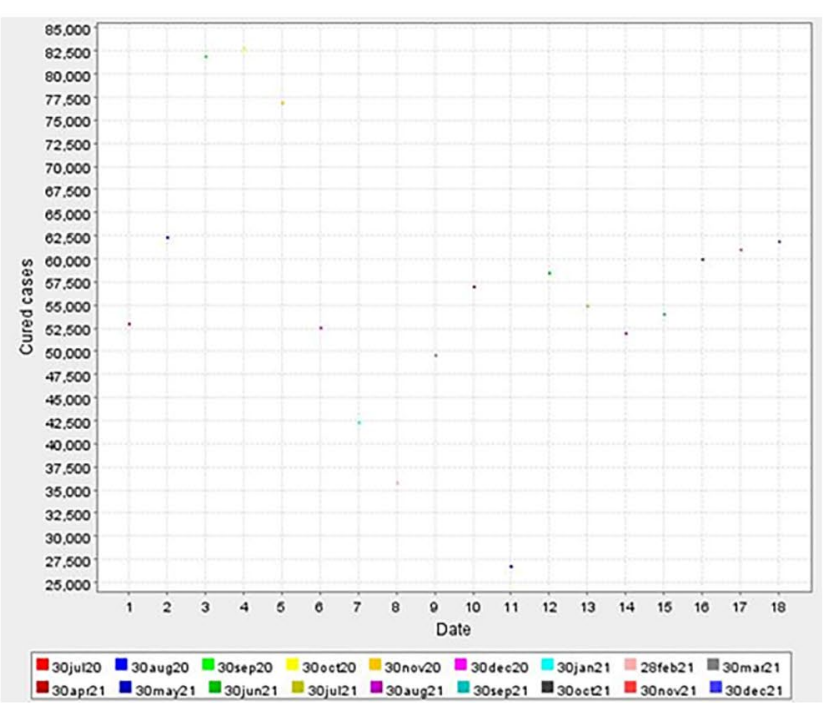

(c)

Fig. 7 a The number of infected cases per day in India from 6 July 2020 to 31 December 2021. b The number of death cases per day in India from 6 July 2020 to 31 December 2021. c The number of cured cases per day in India from 6 July 2020 to 31 December 2021

on the mathematical model of Government actions and individual reactions, we have predicted the number of infected, death, and cured cases from 6 July 2020 to January 2022 . By the simulation process, we found that the number of infected cases will increase by approximately 40,000 per day Fig. 3a, b; death cases will also reach approximately 600 per day Fig. 4a, b, and cured cases will touch approximately 30,000 (Fig. 5) and above per day up to January 2022. So, by this simulation, we can predict that India may shift to a more critical hit, record 1 lakh COVID-19 cases daily, and 1000 death cases by May 2021 (2.87 lakh cases daily predicted by MIT study (Zhao et al. 2020b)).
This task's primary objective is to introduce a mathematical model to discuss the personal response, governmental action, and time-varying reporting rate. We offer a fair study of individual responses and administrative steps to catch the recognized pattern.

\section{Rough sets}

The rough set applications utilized today are considerably more extensive than before, basically in the drug zones, investigation of database traits, and process control. The 


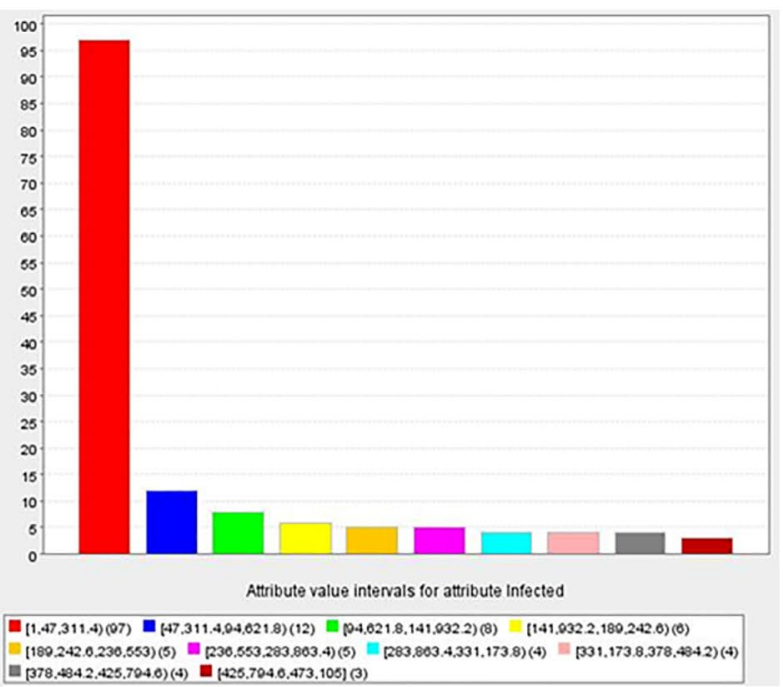

(a)

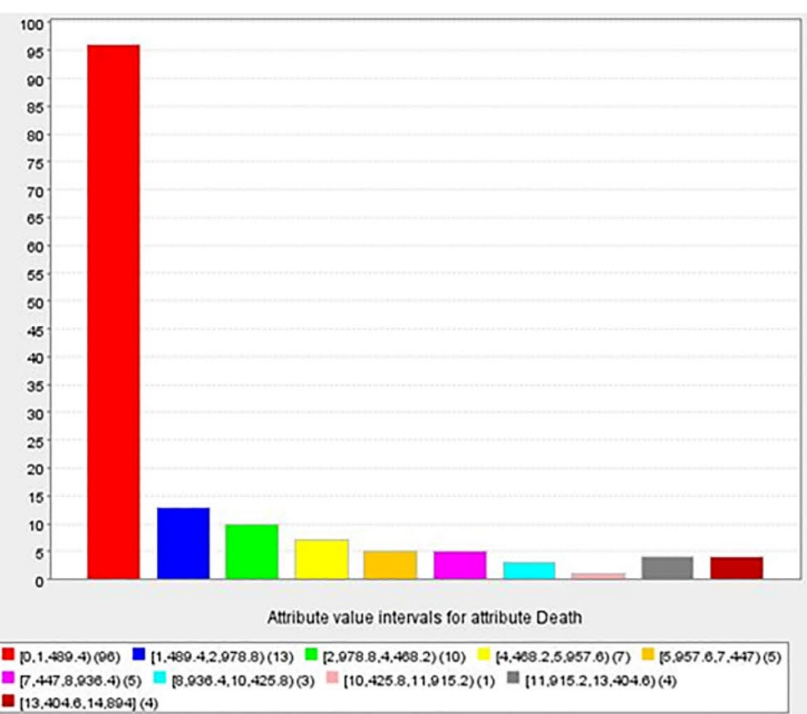

(b)

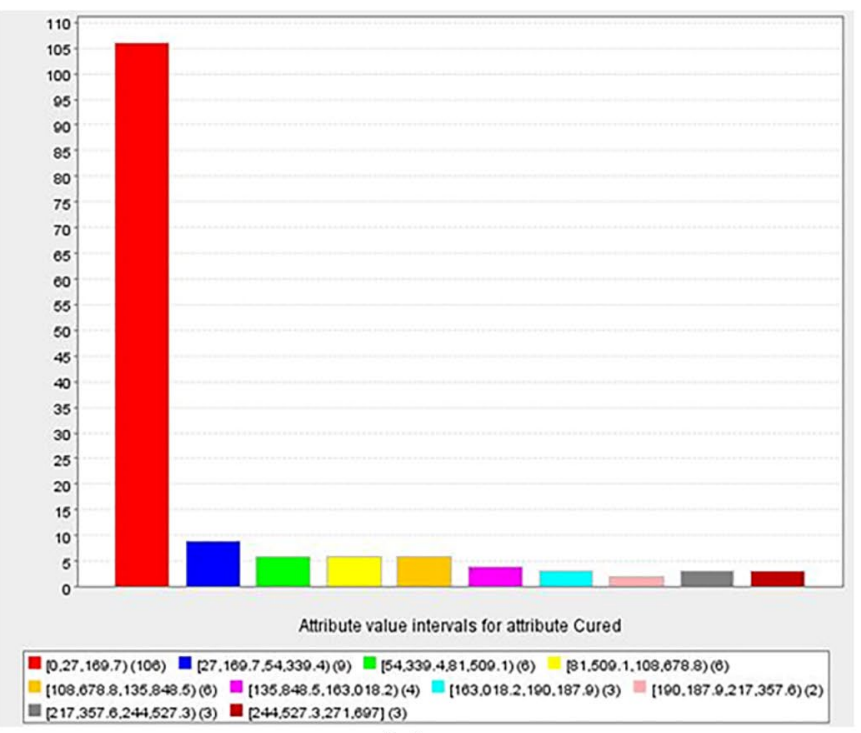

(c)

Fig. 8 a Attribute value intervals for attribute "infected". b Attribute value intervals for attribute "death". c Attribute value intervals for attribute "cured"

rough set has a few covers with different strategies for information examination, e.g., cluster investigation, fuzzy sets, statistics, proof hypothesis, and others, yet very well may be seen in its rights as a free control (Zhao et al. 2020c; The Week et al. 2020; Polkowski 2002).

\subsection{Validation by the Rough set}

The dataset (Corona virus disease (COVID-19 INDIA) 2020) describes the model as further relevant because we only require the infected, dead, and cured cases of COVID19 , seeking the expected number of infected, dead, and cured cases by the model. We noticed these preliminary data in the precise form. The data are sound and very proper for working in the model.

The dataset (Corona virus disease (COVID-19 INDIA) 2020) of the infected, dead, and cured cases of COVID19 with time (days) was taken from 30 January 2020 to 25 June 2020 as a lower approximation, 30 January 2020 to 30 November 2020 as an upper approximation, 26 June 2020 to 05 July 2020 as a boundary region. By using Rough Set Exploration System (RSES 2.2.2) (Peters et al. 2012), it is observed that the number of infected cases is increasing with time (days) (Fig. 6a), the number of 


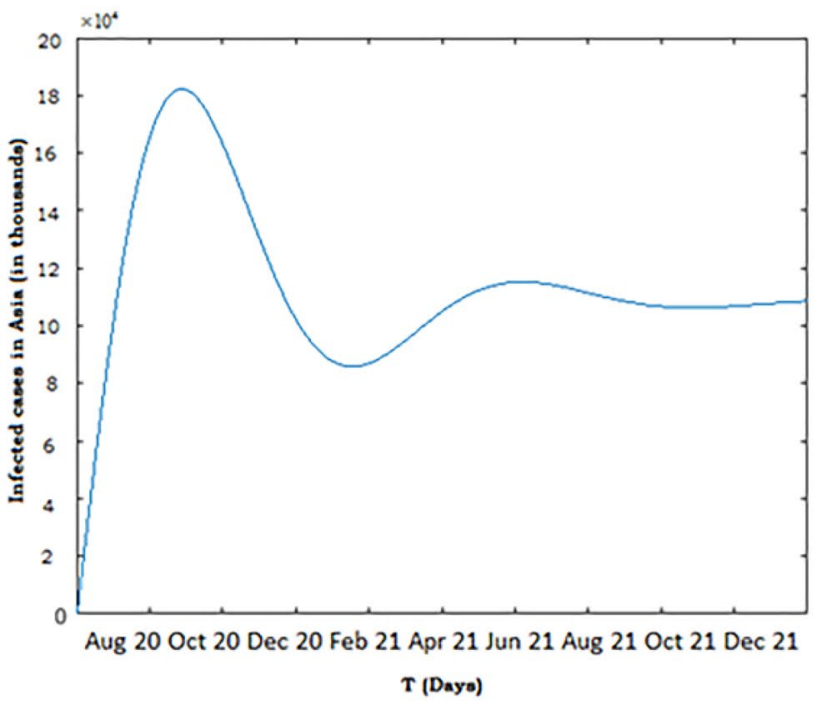

(a)

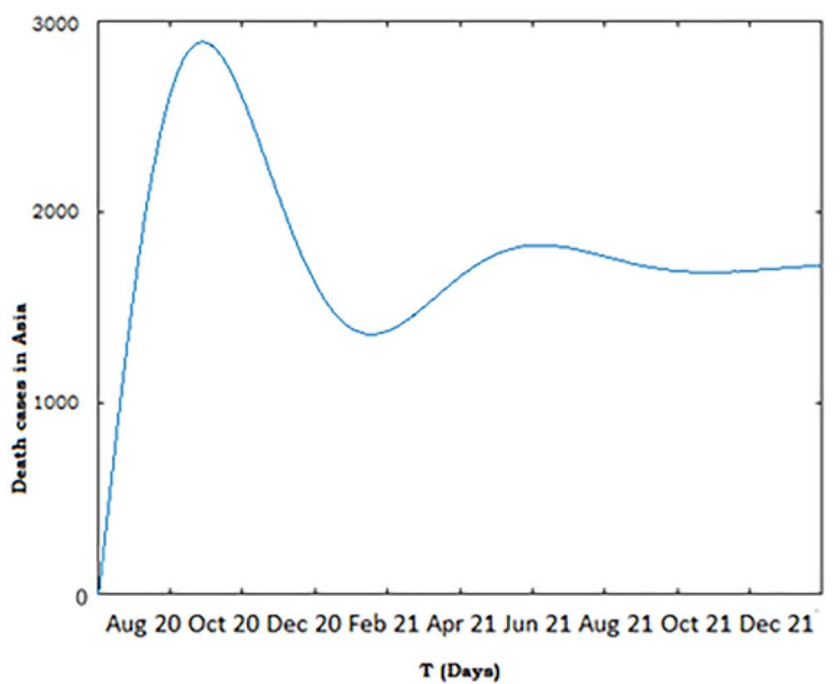

(b)

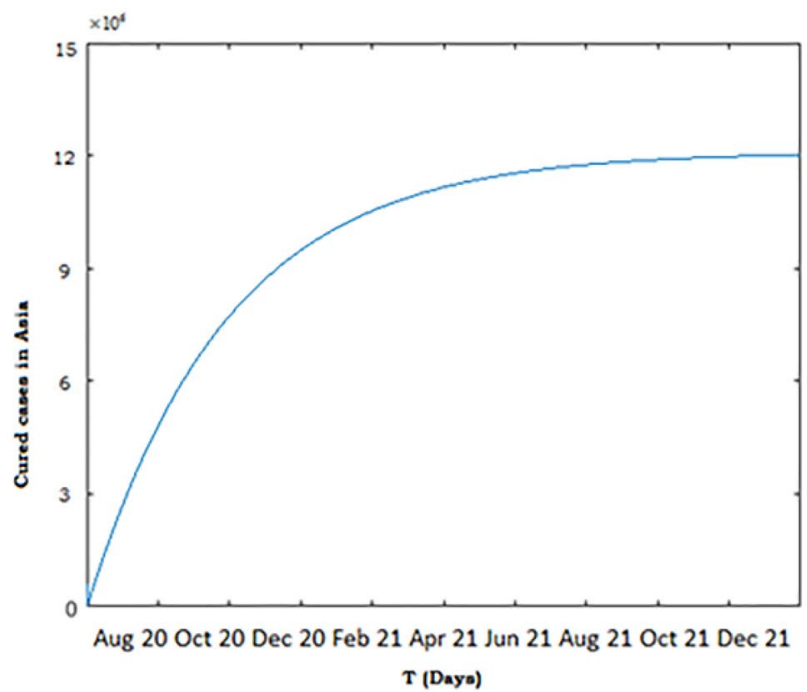

(c)

Fig. 9 (a) The number of infected cases of Asia per day predicted by simulation from 6 July 2020 to 31 December 2021. b The number of death cases of Asia per day predicted by simulation from 6 July 2020

death cases increasing with time Fig. 6b, and the number of cured cases also increasing with time (days) Fig. 6c.

\subsection{The mechanism used for the rough set}

A data frame comprising information $\mathrm{S}=(\rho, \sigma)$, where $\rho$ is the collection of objects and $\vartheta$ is the collection of characteristics, $\vartheta \subseteq \rho$ and $\lambda \subseteq \sigma$. The two sets $\lambda_{*}(\vartheta)$ and $\lambda^{*}(\vartheta)$ represent the lower and upper estimate of $\vartheta$, respectively, and described as follows (Zhao et al. 2020c; The Week et al. 2020; Polkowski 2002): to 31 December 2021. c The number of cured cases of Asia per day predicted by simulation from 6 July 2020 to 31 December 2021

$\lambda_{*}(\vartheta)=\cup_{x \in \rho}\{\lambda(x): \lambda(x) \subseteq \vartheta\}$
$\lambda^{*}(\vartheta)=\bigcup_{x \in \rho}\{\lambda(x): \lambda(x) \cap \vartheta \neq \phi\}$

The set

$\lambda N_{\lambda}(\vartheta)=\lambda^{*}(\vartheta)-\lambda_{*}(\vartheta)$

is described as the boundary area of 9 Zhao et al. 2020c; The Week et al. 2020; Polkowski 2002) (Lin and Cercone 1997; Skowron 2005; Sinha et al. 2018, 2020; Sinha and Namdev 2020a, b, c, 2021a, b; Namdev and Sinha 2020, 2021). 
Table 2 The comparison of infected, death and cured cases found by the simulation process and real data

\begin{tabular}{lllllll}
\hline Date & $\begin{array}{l}\text { Actual infected } \\
\text { cases (reported)* }\end{array}$ & $\begin{array}{l}\text { Infected cases found } \\
\text { by simulation }\end{array}$ & $\begin{array}{l}\text { Actual death cases } \\
\text { (reported) }\end{array}$ & $\begin{array}{l}\text { Death cases found } \\
\text { by simulation }\end{array}$ & $\begin{array}{l}\text { Actual cured cases } \\
\text { (reported)* }\end{array}$ & $\begin{array}{l}\text { Cured cases } \\
\text { found by simu- } \\
\text { lation }\end{array}$ \\
\hline 26-Jun-20 & 17,296 & 17,258 & 407 & 324 & 13,940 & 10,668 \\
27-Jun-20 & 18,552 & 19,603 & 384 & 380 & 9944 & 11,081 \\
28-Jun-20 & 19,906 & 21,426 & 410 & 415 & 14,131 & 12,410 \\
29-Jun-20 & 19,459 & 22,068 & 380 & 418 & 13,099 & 12,516 \\
30-Jun-20 & 18,522 & 22,291 & 418 & 460 & 13,157 & 13,686 \\
01-Jul-20 & 18,653 & 22,371 & 507 & 598 & 20,032 & 14,221 \\
02-Jul-20 & 19,148 & 22,400 & 434 & 618 & 14,335 & 14,442 \\
03-Jul-20 & 20,903 & 22,410 & 379 & 622 & 623 & 14,856 \\
04-Jul-20 & 22,771 & 22,413 & 442 & 624 & 15,367 \\
05-Jul-20 & 24,850 & 22,414 & 613 & & 15,369 \\
\hline
\end{tabular}

*Actual infected and actual death cases $=$ World Health Organisation $($ WHO)

**Acual cured cases $=$ Ministry of Helath and Family Welfare (MoHFW)

If $\lambda N_{\lambda}(\vartheta)=\phi$, then $v$ is crisp or exact with respect to $\lambda$; and if $\lambda N_{\lambda}(\vartheta) \neq \phi$, then $v$ is rough or inexact with respect to $\lambda$ Zhao et al. 2020c; The Week et al. 2020; Polkowski 2002) (Lin and Cercone 1997; Skowron 2005; Sinha et al. 2018, 2020; Sinha and Namdev 2020a, b, c, 2021a, b; Namdev and Sinha 2020, 2021).

\subsection{The rough set result}

\subsubsection{Training by the rough set}

For training, we have taken data from 30 January 2020 to 25 June 2020, and we found the actual daily and cumulative data for the infected, death, and cured cases. Utilizing the estimated values of infected, death, and cured cases and the RSES, the cumulative infected cases Fig. 6a, the cumulative death cases Fig. 6b, and the cumulative cured cases Fig. 6c that exhibit the number of infected, death, and cured cases are growing with time.

\subsubsection{Testing by the rough set}

In India's context, for testing, we have shown simulated data in Table from 26 June 2020 to 05 July 2020 with the comparison with actual data, and we have also shown our simulations for infected, death, and cured cases in Fig. 7a-c, respectively.

The accuracy also found by the rough set method for the infected case is $90.19 \%$, an infection-fatality rate of COVID19 is approximately $94 \%$, and the recovery rate is $85.57 \%$, which is approximately the same as the data provided by the WHO India report and MoHFW India. We also found that the rate of the infected case is $0.05 \%$, an infection-fatality rate of COVID-19 is approximately $2.90 \%$, and the recovery rate is $59.05 \%$, approximately the same as the data provided by the WHO India report and MoHFW India.

\subsection{Statistics of the "infected cases"}

The "infected cases" are observed by applying the rough set. The mean value of the infected cases is 76191.547 , the standard deviation is 121453.195 , the below value is 1 , and the above is 473105 in Table 3. Figure 8a shows the attribute value intervals for attribute "infected".

From Fig. 8a, we found that 47,310 (width of each interval) infected cases were reported in the first 97 days, but the same number of cases were reported in the next 12 days, after that the next 8 days, then 6 days, 5 days, 4 days, and 3 days, which shows the increasing trend of the infected cases.

Table 3 Statistics of the "number of infected cases" attribute

\begin{tabular}{ll}
\hline Stats of the "infected cases" & \\
\hline Number of objects: 148 & $\begin{array}{l}\text { Attributes: Number of infected cases } \\
\text { Status: condition }\end{array}$ \\
& Type: numeric \\
Number of attributes: 3 & Mean: $76,191.547$ \\
& Standard deviation: $121,453.195$ \\
& Minimum: 1 \\
& Maximum: 473,105 \\
& Attribute range \\
& Lower limit of values: 0 \\
Attributes & Upper limit of values: 473,105 \\
Cured cases &
\end{tabular}


Table 4 Stats of the "death cases" attribute

Stats of the "death cases"

Number of objects: 148

Attributes: Number of death cases

Status: condition

Number of attributes: 3

Death cases

Type: numeric

Mean: 2312.811

Standard deviation: 3731.951

Minimum: 0

Maximum: 14,894

Attribute range

Lower limit of values: 0

Upper limit of values: 14,894

Table 5 Stats of the "cured cases"

\begin{tabular}{ll}
\hline Stats of the "cured cases" & \\
\hline Number of objects: 148 & $\begin{array}{l}\text { Attributes: Number of cured cases } \\
\text { Status: condition }\end{array}$ \\
Number of attributes: 3 & Type: numeric \\
& Mean: $36,042.108$ \\
& Standard deviation: $64,913.058$ \\
& Minimum: 0 \\
& Maximum: 271,697 \\
& Attribute range \\
& Lower limit of values: 0 \\
Attributes & Upper limit of values: 271,697 \\
Cured cases &
\end{tabular}

\subsection{Statistics of the "death cases"}

The "death cases" are observed by applying the rough set. The mean value of the death cases is 2312.811 , the standard deviation is 3731.951 , the below value is 0 , and the above value is 14,894 in Table 4 . Figure 8 b shows the attribute value intervals for attribute "death".

From Fig. 8b, we found that 1489 (width of each interval) death cases were reported in the first 96 days, but the same number of cases was reported in the next 13 days, after that the next 10 days, then 7 days, 5 days, 3 days, 1 day, and 4 days, which shows the increasing trend of the death cases.

\subsection{Statistics of the "cured cases"}

The "cured cases" are observed by applying the rough set. The cured cases' mean value is 36042.108 , the standard deviation is 64913.058 , the below value is 0 , and the above value is 271697 in Table 5. Figure 8c shows the attribute value intervals for attribute "cured".
From Fig. 8c, we found that 27,170 (width of each interval) cured cases were reported in the first 106 days, but the same number of cases were reported in the next 9 days, after that the next 6 days, then 4 days, and 2 days, which shows the increasing trend of the cued cases.

\section{The worldwide impact of COVID-19}

The coronavirus COVID-19 is affecting 213 countries and territories around the world (Naik and Pardasani 2018). The major coronavirus impact can be seen in South America, Asia, North America, Europe, and Africa. Developing a vaccine against COVID-19 is one of the most pressing challenges of our time (Corona virus disease (COVID-19) 2020). By this assumption, we have predicted the global impact of the COVID-19.

\subsection{Infected, deaths, and cured cases of Asia by the simulation}

We found that the number of new infected, deat,h and total cured cases per day in Asia were 107,145, 1401, and $14,340,801$, respectively, by 24 November 2020 (Naik and Pardasani 2018), which were approximately in line with the simulation process (i.e., approximately 105,000, 1700, and 13,000,000 respectively) Fig. 9a-c. The number of new infected, death, and total cured cases per day in Asia were $108,260,1768$, and $14,427,723$, respectively, by 25 November 2020 (Naik and Pardasani 2018), which were approximately in line with the simulation process (i.e., approximately $105,000,1700$, and $13,000,000$, respectively) Fig. 9a-c. The number of new infected, death, and total cured cases per day in Asia were 109,964, 1766, and 14,513,781, respectively, by 26 November 2020 (Naik and Pardasani 2018), which were approximately in line with the simulation process (i.e., approximately 105,000, 1700, and 13,000,000, respectively) Fig. 9a-c.

\subsection{Infected, deaths, and cured cases of North America by the simulation}

The number of new infected, death and total cured cases per day in North America were 194,218, 2636, and $9,268,835$, respectively, by 24 November 2020 (Naik and Pardasani 2018), which were approximately in line with the simulation process (i.e., approximately 180,000 , 3000 , and 8,000,000 respectively) Fig. 10a-c. The number of new infected, death and total cured cases per day in North America were 201,600, 3265, and 9,451,101, 


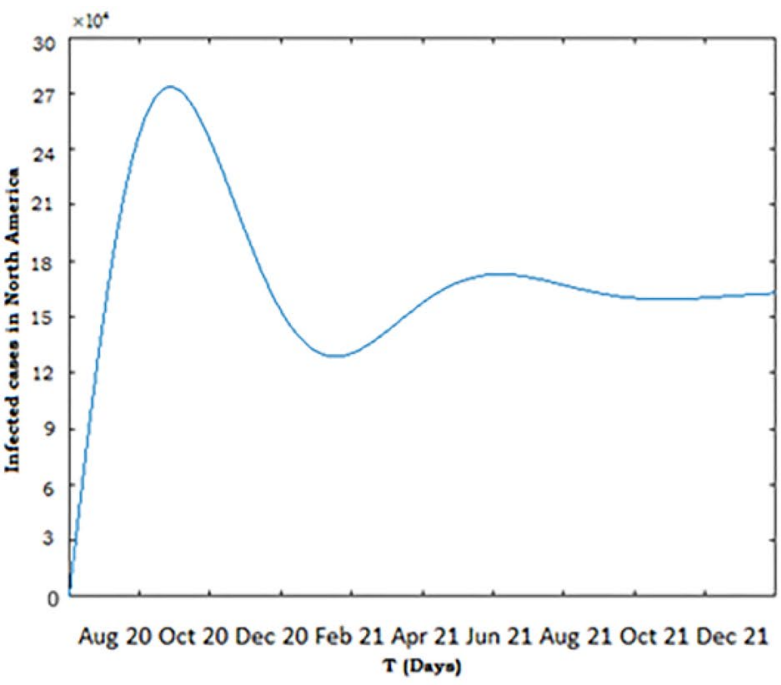

(a)

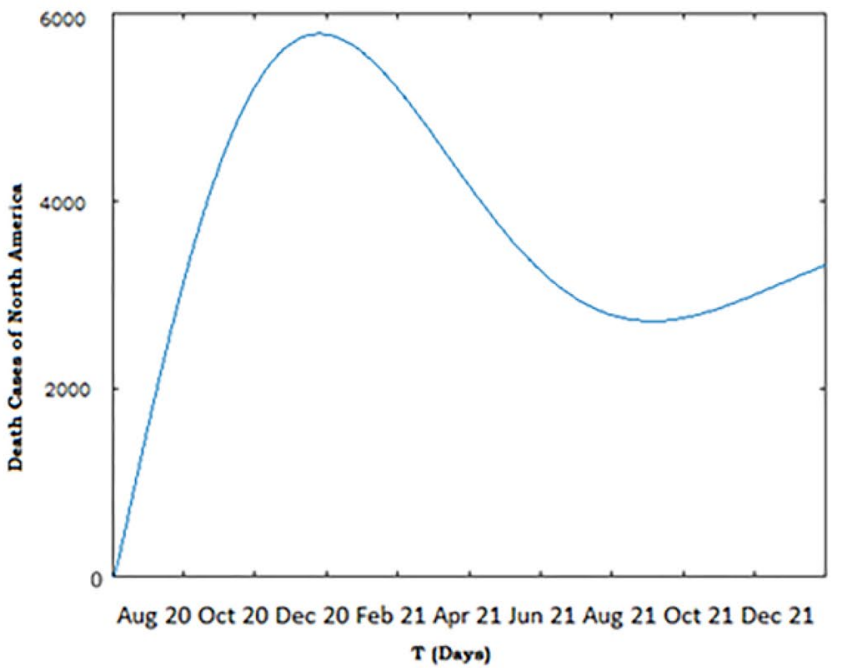

(b)

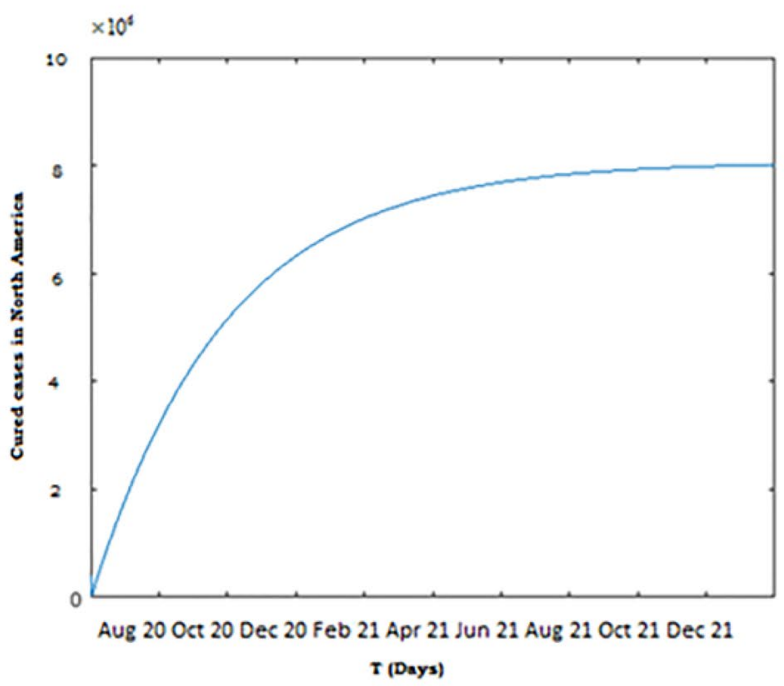

(c)

Fig. 10 a The number of infected cases of North America per day predicted by simulation from 6 July 2020 to 31 December 2021. b The number of death cases of North America per day predicted by

respectively, by 25 November 2020 (Naik and Pardasani 2018), which were approximately in line with the simulation process (i.e., approximately 180,000, 3000, and $8,000,000$ respectively) Fig. $10 \mathrm{a}-\mathrm{c}$. The number of new infected, death and total cured cases per day in North America were 130,194, 2324, and 9,506,276, respectively, by 26 November 2020 (Naik and Pardasani 2018), which were approximately in line with the simulation process (i.e., approximately 180,000, 3000, and $8,000,000$ respectively) Fig. 10a-c. simulation from 6 July 2020 to 31 December 2021. c The number of cured cases of North America per day predicted by simulation from 6 July 2020 to 31 December 2021

\subsection{Infected, deaths, and cured cases of South America by the simulation}

The number of new infected, death and total cured cases per day in South America were 52,197, 1281, and 9,713,591, respectively, by 24 November 2020 (Naik and Pardasani 2018), which were approximately in line with the simulation process (i.e., approximately 52,000, 1000, and 8,000,000 respectively) (Fig. 11a-c). The number of new infected, death and total cured cases per day in South America were $67,984,1189$, and $9,768,912$, respectively, by 25 November 


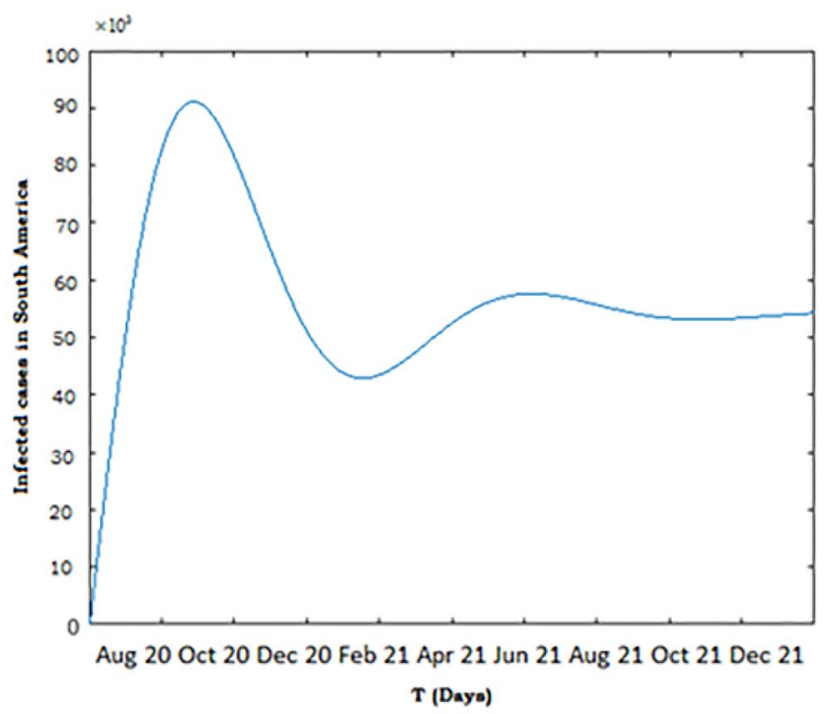

(a)

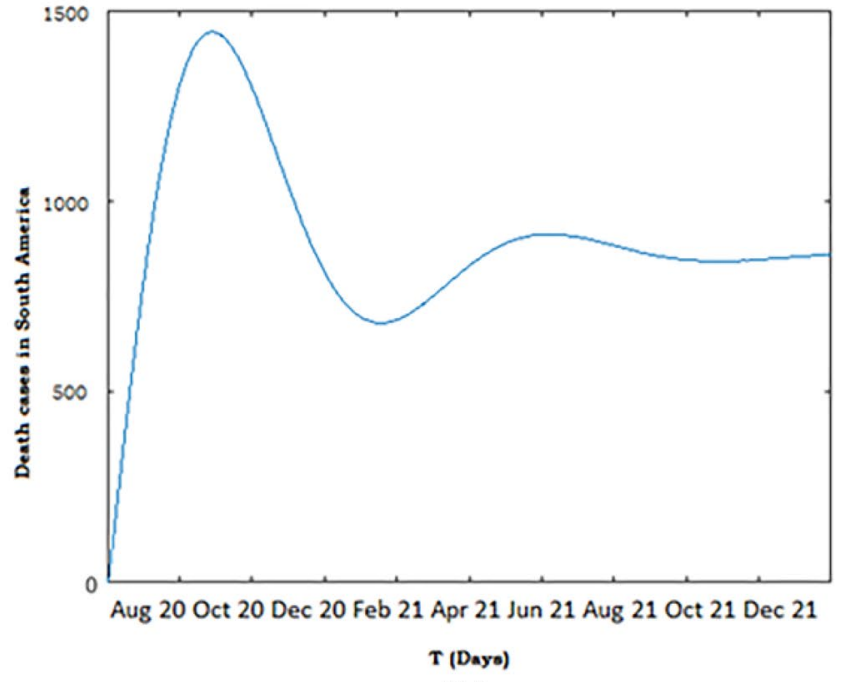

(b)

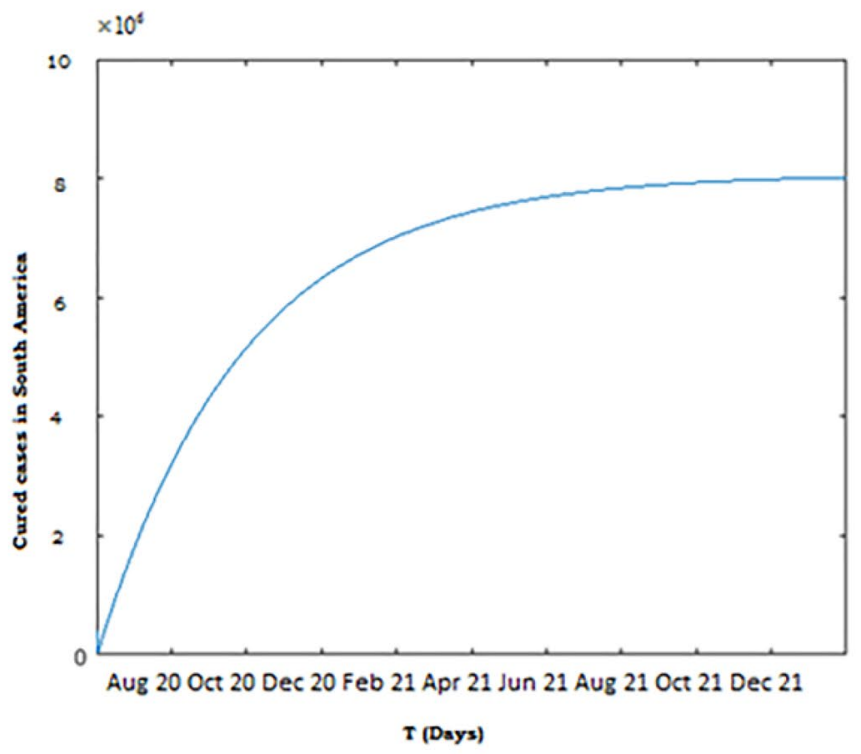

(c)

Fig. 11 a The number of infected cases of South America per day predicted by simulation from 6 July 2020 to 31 December 2021. b The number of death cases of South America per day predicted by

2020 (Naik and Pardasani 2018), which were approximately in line with the simulation process (i.e., approximately 52,000, 1000, and 8,000,000 respectively) Fig. 11(a-c). The number of new infected, death and total cured cases per day in South America were 61,936, 1292, and 9,805,546, respectively, by 26 November 2020 (Naik and Pardasani 2018), which were approximately in line with the simulation process (i.e., approximately 52,000, 1000, and 8,000,000 respectively) (Fig. 11a-c). simulation from 6 July 2020 to 31 December 2021. c The number of cured cases of South America per day predicted by simulation from 6 July 2020 to 31 December 2021

\subsection{Infected, deaths, and cured cases of Europe by the simulation}

The number of new infected, death and total cured cases per day in Europe was 182,762, 5764, and 6,404,265, respectively, by 24 November 2020 (Naik and Pardasani 2018), which were approximately in line with the simulation process (i.e., approximately 170,000, 4000 , and 7,000,000 respectively) (Fig. 12a-c). The 


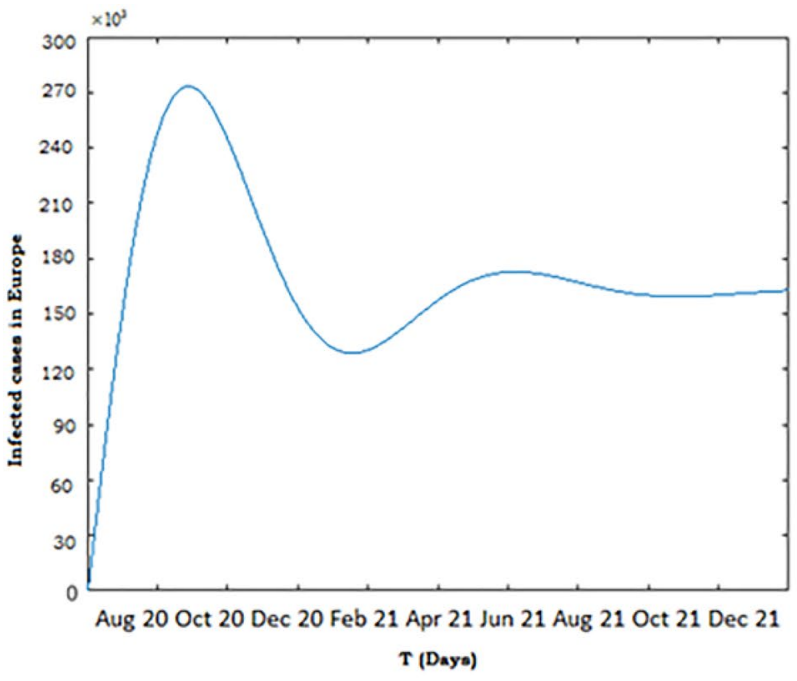

(a)

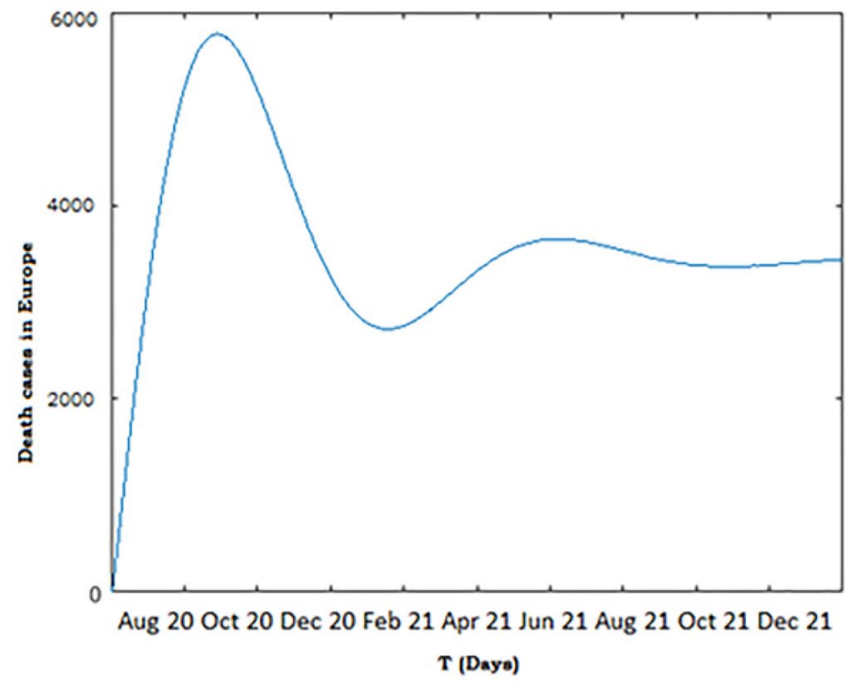

(b)

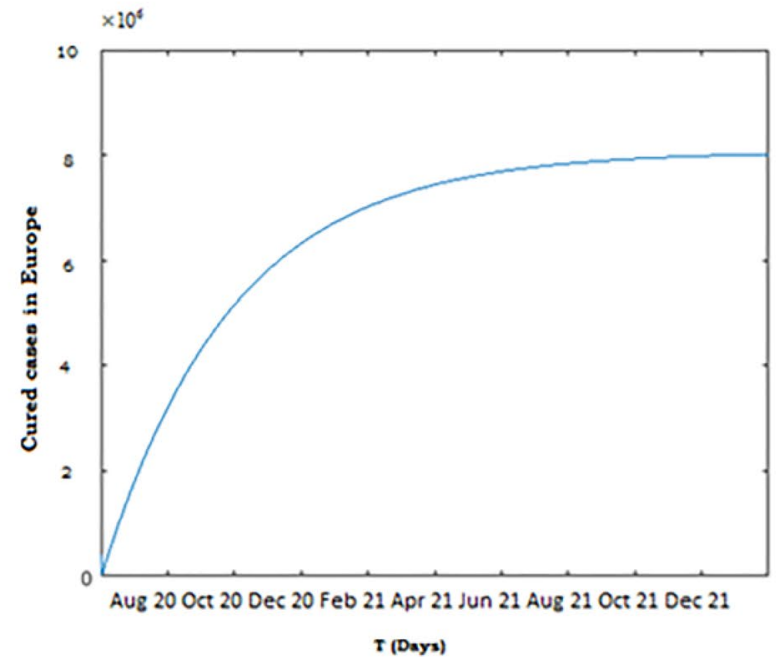

(c)

Fig. 12 a The number of infected cases of Europe per day predicted by simulation from 6 July 2020 to 31 December 2021. b The number of death cases of Europe per day predicted by simulation from 6 July

number of new infected, death and total cured cases per day in Europe was 216,449, 5469, and 6,548,780, respectively, by 25 November 2020 (Naik and Pardasani 2018), which were approximately in line with the simulation process (i.e., approximately 170,000, 4000, and 7,000,000 respectively) (Fig. 12a-c). The number of new infected, death and total cured cases per day in Europe was 225,067, 5276, and 6,726,325, respectively, by 26 November 2020 (Naik and Pardasani 2018), which were approximately in line with the simulation process (i.e., approximately 170,000 , 4000 , and 7,000,000 respectively) (Fig. 12a-c).
2020 to 31 December 2021. c The number of cured cases of Europe per day predicted by simulation from 6 July 2020 to 31 December 2021

\subsection{Infected, deaths, and cured cases of Africa by the simulation}

The number of new infected, death and total cured cases per day in Africa were 14,270, 431, and 693,620, respectively, by 24 November 2020 (Naik and Pardasani 2018), which were approximately in line with the simulation process (i.e., approximately $13,000,320$, and 1,800,000 respectively) (Fig. 13a-c). The number of new infected, death and total cured cases per day in Africa were $13,563,439$, and 707,877, respectively, by 25 November 2020 (Naik and Pardasani 2018), which were approximately in line with the simulation process (i.e., approximately 13,000, 


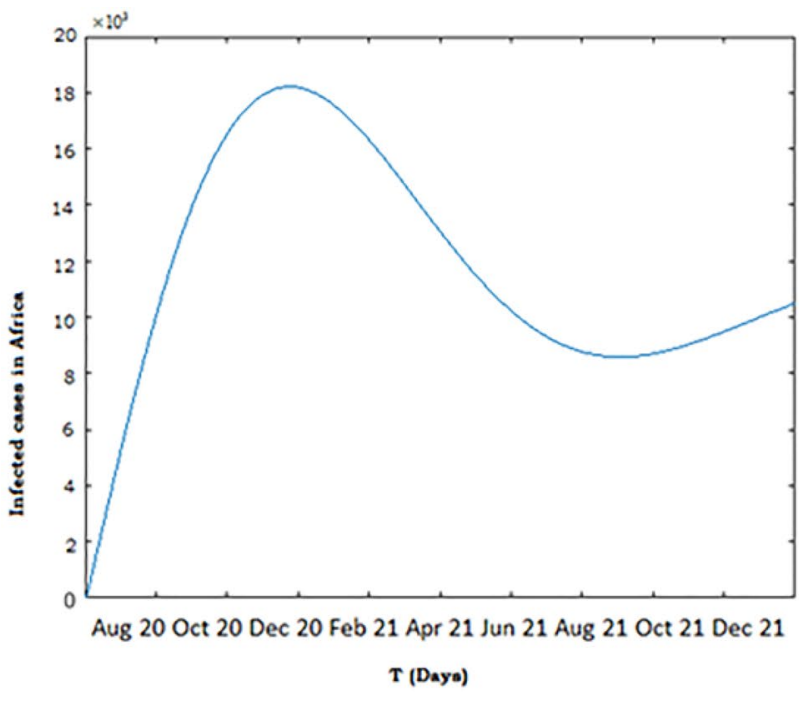

(a)

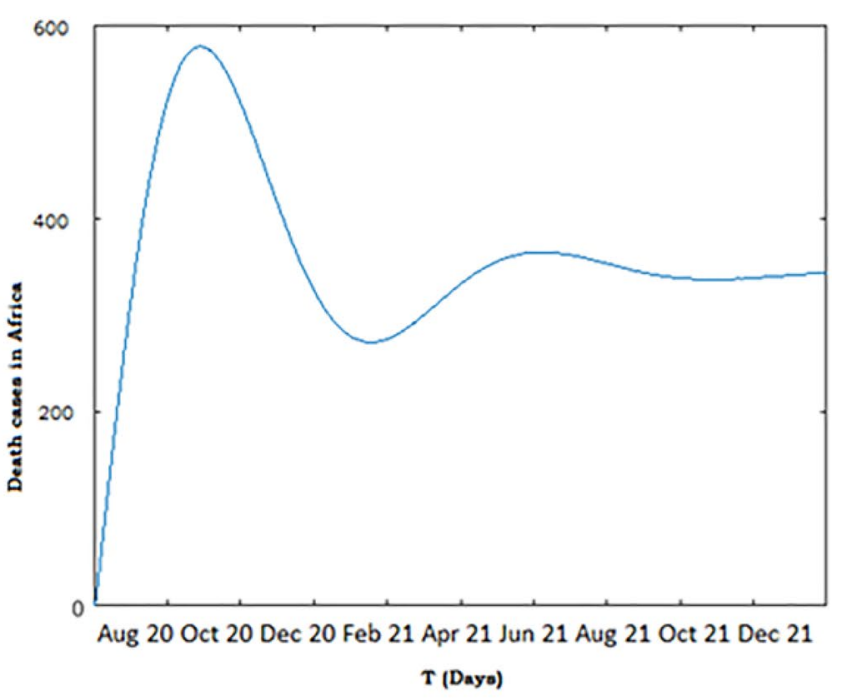

(b)

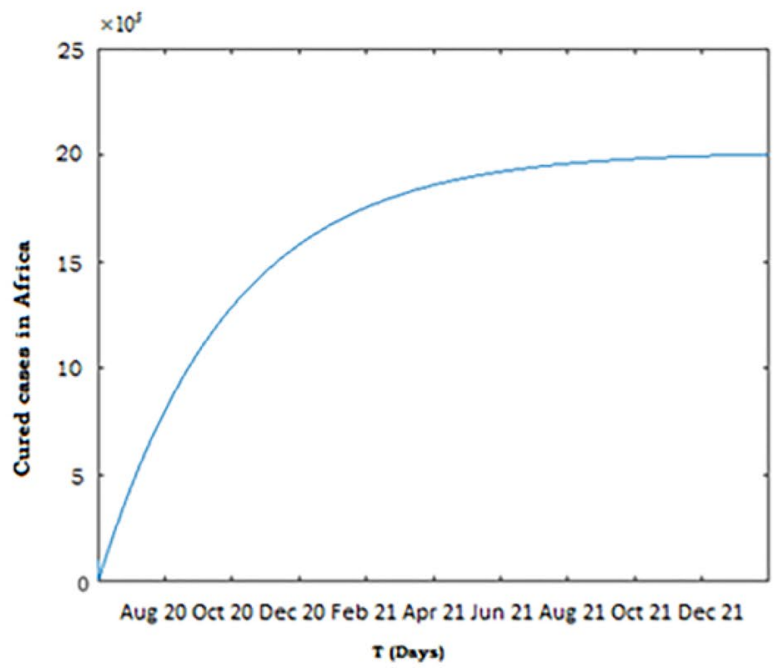

(c)

Fig. 13 a The number of infected cases of Africa per day predicted by simulation from 6 July 2020 to 31 December 2021 . b The number of death cases of Africa per day predicted by simulation from 6 July

320, and 1,800,000 respectively) (Fig. 13a-c). The number of new infected, death and total cured cases per day in Africa were $13,927,297$, and 1,800,753, respectively, by 26 November 2020 (Naik and Pardasani 2018), which were approximately in line with the simulation process (i.e., approximately 13,000, 320, and 1,800,000 respectively) (Fig. 13a-c).

\section{Discussion}

The coronavirus is a dangerous condition for human beings and creates an enormous hazard to health. A global multilevel interaction with plenty of circumstances varying from
2020 to 31 December 2021. c The number of cured cases of Africa per day predicted by simulation from 6 July 2020 to 31 December 2021

physical and financial factors forces the advancement of highly modern mathematical models for the sound presentation of infectious dynamics of diseases (i.e., COVID-19). To control the outbreak of diseases, India's government has ordered the ending of vital functions through lockdown to restrict the coronavirus disease.

So, we observe that when the Government of India has taken strict action enforcing control measures like lockdown 1.0, 2.0, 3.0 up to 31 May 2020 (Corona virus disease (COVID-19 INDIA) 2020), the involvement of people of India is less, the rate of infection and death by COVID -19 is less in Fig. 1a, b, respectively. After 1 June 2020, from unlock 1.0 and unlock 2.0 (Corona virus disease (COVID-19 
INDIA) 2020), we observe the spread of COVID -19 in terms of infection, death, and cure, increasing in nature (Fig. 1a). The facts and control measures implemented in India for COVID - 19 are given in Table 1. However, the death rate and recovery rate have also increased (Fig. 1b, c). We have simulated the whole scenario using parameters like governmental actions, transmission rate, total initial population, initial susceptible population, mean latent period, mean infectious period, the proportion of severe cases, and mean duration of public reactions. We apply the rough set to validate the model, and we obtain that the model is near the actual situation. Using the simulation and rough set model, we try to predict the trend of the corona pandemic in India in the future for infected, death, and cured cases, respectively, in Figs. 3, 4, 5, when no proper medicine is available as a drug target on COVID -19 and no vaccination of COVID -19 is available as a precautionary measure in the society.

The number of daily real infected cases in India was 24,850 by 05 July 2020 , approximately in line with the simulation process (i.e., 22,414) (Table 2). Likewise, the number of daily death cases in India was 613 by 05 July 2020 , approximately in line with the simulation process (i.e., 624) (Table 3). In the same way, we have also found that the number of daily cured cases in India was 14,856 by 05 July 2020 , which is approximately in line with the simulation process (i.e., 15,369) (Table). So, the mathematical model's interpretation is near the actual situation of the COVID-19 pandemic in India. The accuracy for the infected case is $90.19 \%$, an infection-fatality of COVID-19 is approximately 94\%, and the recovery is $85.57 \%$, which are approximately the same as the WHO India report's data and Ministry of Health and Family Welfare (MoHFW) India.

In the assumption part, we have assumed that "If people get infected once, they can get infected once again". In the present scenario, we have seen that those who are vaccinated are also getting infected. Therefore, no need to incorporate the vaccination to study the system.

We found the rate of infected cases against the total population is $0.05 \%$ ( $0.04 \%$ reported by the Government of India), and the infection-fatality rate of COVID-19 is $2.90 \%$ (2.82\% reported by the Government of India) till 05 July 2020 . The recovery rate is $59.05 \%$ (60.77\% reported by the Government of India) till 05 July 2020 in India's context, and we also observed that the rates of infection, infection-fatality rate, and recovery rate are increasing in nature. We have also validated our model by the rough set and found the same level of accuracy.

\section{Conclusion}

Due to physical and financial factors, the population density is more likely to interact and spread the virus. Various scientific models have been explained to represent the progression of casualties resulting from coronavirus COVID-19 globally. In this mathematical model, we support conceptual criteria to prevent the spread of the COVID-19 in India and worldwide by the idea of different people's reactions and administrative healthcare policy. By using the rough set, we also found that 47,310 infected cases were reported in the first 97 days, but the same number of cases were reported in the next 12 days, after that the next 9 days, then 6 days, 5 days, 4 days, and 3 days, and that shows the increasing trend of the infected cases. The 1489 death cases were reported in the first 96 days, but the same number of cases were reported in the next 13 days, after that the next 10 days, then 7 days, 5 days, 3 days, 1 day, and 4 days and that shows the increasing trend of the death cases. Similarly, the 27,170 cured cases were reported in the first 106 days, but the same number of cases were reported in the next 9 days, after that the next six 6 days, then 4 days, and 2 days, which shows the increasing trend of the cured cases.

The holistic, sound solutions to health crises are the policymakers' primary concern (Singh and Adlakha 2019; COVID-19 Coronavirus Pandemic. xxxx). The global level's active health actions are only possible due to the health function's decentralization (Higginson et al. 2020). Our model's merit is that we analyzed some vital components, including individual reaction, regulatory actions, and movement of a high proportion of the population quickly. Meantime, our model is comparatively modest, and estimations are in order with earlier investigations (Wu et al. 2020a, b; modelling study. 2020; Mahase 2020; Bekiros and Kouloumpou 2020; Barmparis and Tsironis 2020; Yousefpour et al. 2020; Contreras et al. 2020; Ivorra et al. 2020; Liang 2020; Li et al. 2020; Wu and McGoogan 2020; Chou and Friedman 2016; Guan et al. 2020; Nishiura et al. 2020a, 2020b; Tuite and Fisman 2020; Zhao et al. 2020a; January 2020) (Xu et al. 2020; Tiirinki et al. 2020) and close to the actual situation (Corona virus disease (COVID-19) 2020; Corona virus disease (COVID-19 INDIA) 2020).

With the mathematical model of Government actions and individual reactions, we have predicted the number of infected, death, and cured cases from 6 July 2020 to 31 December 2021. By the simulation process, we found that the number of infected cases will increase by approximately 40,000 per day; death cases will also reach approximately 600 per day, and cured cases will touch approximately 30,000 and above per day up to 31 December 2021 (2.87 lakh cases daily predicted by MIT study (Zhao et al. 2020b)). As the pandemic is uncertain due to different variants of the coronavirus, it would be impossible to find the equilibrium point during the study period. However, it would be found in an equilibrium state after December 2021, when the situation will be approaching to the certainty of the variants of the coronavirus. 
In this paper, we use the generalized simulation process of the outbreak of COVID-19 for different continents. By changing continents' initial population size, we have predicted the future trend of the COVID-19 on different continents. Using these parameters, the simulation process predicted the infected, death, and cured cases worldwide. We have seen that the impact of the pandemic will still rise in continents like Asia (Fig. 9a-c), and then North America (Fig. 10a-c), South America (Fig. 11a-c), Europe (Fig. 12a-c), and Africa (Fig. 13a-c).

In work, we concentrated on the transmission of COVID19 in India and successively for the global scenario with public involvement and Government efforts. Our model can be suited to everyday data and can make a pillar for future research work. The model helps to impose new control measures to break the spread of corona worldwide.

Acknowledgements The authors are very grateful to NIT Raipur (Chhattisgarh), India, for giving facilities, space, and an opportunity for the work, and the corresponding author would like to thank Chhattisgarh Council of Science and Technology (CCOST), Raipur, for financial support through the research project number: 1742/CCOST/ R\&D/2020 Raipur.

\section{Declarations}

Conflict of interest The authors declare that there is no conflict of interest.

\section{References}

Barmparis GD, Tsironis GP (2020) Estimating the infection horizon of COVID-19 in eight countries with a data-driven approach. Chaos Solitons Fractals 135:109842. https://doi.org/10.1016/j.chaos. 2020.109842

Bekiros S, Kouloumpou D (2020) SBDiEM: a new mathematical model of infectious disease dynamics. Chaos Solitons Fractals 136:109828. https://doi.org/10.1016/j.chaos.2020.109828

Chan JFW, Yuan S, Kok KH, Wang KK, Chu H, Yang J, Xing F, Liu J, Yip CCY, Poon RWS, Tsoi HW, Lo SKF, Chan KH, Poon VKM, Chan WM, Danial J, Cai JP, Cheng VCC, Chen H, Hui KM, Yuen KY (2020) A familiar cluster of pneumonia associated with the 2019 novel coronavirus indicating person-toperson transmission: a study of a family cluster. The Lancet 395:514-523. https://doi.org/10.1016/S0140-6736(20)30154-9

Chou CS, Friedman A (2016) Introduction to the mathematical biology. Springer Internat Pub Switz. https://doi.org/10.1007/ 978-3-319-29638-8

Cohen J (2020) Mining coronavirus genomes for clues to the outbreak's origins. Science. https://www.sciencemag.org/news/ 2020/01/mining-coronavirus-genomes-clues-outbreak-s-origi ns. (Accessed 31 Janu 2020)

Contreras S, Villavicencio HA, Ortiz DM, Lattes JPB, Nappa AO (2020) A multi-group SEIRA model for the spread of COVID19 among heterogeneous populations. Chaos Solitons Fractals 136:109925. https://doi.org/10.1016/j.chaos.2020.109925

Corona virus disease (COVID-19 INDIA) (2020), Ministry of Health and Family Welfare (MoHFW). https://www.mohfw.gov.in/
Corona virus disease (COVID-19) (2020), World Health Organization (WHO). https://www.who.int/health-topics/coronavirus\# $\mathrm{tab}=\mathrm{tab} \_1$

COVID-19 Coronavirus Pandemic. https://www.worldometers.info/ coronavirus/

Guan W, Ni Z, Hu Y, Liang W, Ou C, He J et al (2020) Clinical characteristics of 2019 novel coronavirus infection in China. N Engl J Med. https://doi.org/10.1056/NEJMoa2002032

He D, Dushoff J, Day T, Ma J, Earn DJ (2013) Inferring the causes of the three waves of the 1918 influenza pandemic in England and Wales. Proc Royal Soc: Biol Sci 280:20131345. https://doi. org/10.1098/rspb.2013.1345

Higginson S, Milovanovic K, Gillespie J, Matthews A, Williams C, Wall L, Moy N, Hinwood M, Melia A, Paolucci F (2020) COVID-19: the need for an Australian economic pandemic response plan. Health Policy Technol 9:488-502. https://doi. org/10.1016/j.hlpt.2020.08.017

Ivorra B, Ferrández MR, Pérez MV, Ramos AM (2020) Mathematical modeling of the spread of the coronavirus disease 2019 (COVID-19) taking into account the undetected infections: the case of China. Commun Nonlinear Sci Num Simul 88:105303. https://doi.org/10.1016/j.cnsns.2020.105303

Kuhl E (2020) Data-driven modeling of COVID-19-Lessons learned. Extr Mech Lett 40:100921. https://doi.org/10.1016/j. eml.2020.100921

Kupferschmidt K (2020) Study claiming new corona virus can be transmitted by people without symptoms was flawed, Science. https://www.sciencemag.org/news/2020/02/paper-non-sympt omatic-patient-transmitting-coronavirus-wrong. (Accessed 3 Feb 2020)

Li Y, Wang B, Peng R, Zhou C, Zhan Y, Liu Z, Jiang X, Zhao B (2020) Mathematical modeling and epidemic prediction of COVID-19 and its significance to epidemic prevention and control measures. Ann Infect Dis Epidemiol 5:1052. https://www. remedypublications.com/annals-of-infectious-disease-and-epide miology-abstract.php?aid $=5755$

Liang K (2020) Mathematical model of infection kinetics and its analysis for COVID-19, SARS and MERS. Infect Genet Evol 82:104306. https://doi.org/10.1016/j.meegid.2020.104306

Lin TY, Cercone N (1997) Rough sets and data mining analysis of imprecise data. Kluwer Acad Publ. https://doi.org/10.1007/ 978-1-4613-1461-5

Liu T, Hu J, Kang M, Lin L, Zhong H, Xiao J, et al. (2020) Transmission dynamics of 2019 novelcoronavirus (2019-nCoV). https:// doi.org/10.2139/ssrn.3526307

Mahase E (2020) Coronavirus: UK screens direct flights from Wuhan after US case. Br Med J Pub Group 368:m265. https://doi.org/10. 1136/bmj.m265

Naik PA, Pardasani KR (2018) 2D finite-element analysis of calcium distribution in oocytes. Netw Model Anal Health Inform Bioinform. https://doi.org/10.1007/s13721-018-0172-2

Namdev N, Sinha AK (2020) Mathematical analysis for the prediction of tumors. Internat J Adv Res Eng Technol 11:644-652. https:// doi.org/10.34218/IJARET.11.8.2020.063

Namdev N, Sinha AK (2021) Prediction of the supportive vaccine type of the covid-19 for public health. J Mathe Comput Sci 11:57035719. https://doi.org/10.28919/jmcs/5738

Nishiura H, Linton NM, Akhmetzhanov AR (2020b) Serial interval of novel coronavirus (2019-nCoV) infections. Int J Infect Dis 93:244-286. https://doi.org/10.1016/j.ijid.2020.02.060

Nishiura H, Kobayashi T, Yang Y, Hayashi K, Miyama T, Kinoshita R, et al. (2020) The rate of under ascertainment of novel Coronavirus (2019-nCoV) infection: estimation using Japanese passengers data on evacuation flights. J Clin Med 9:419. https://www.mdpi.com/ 2077-0383/9/2/419. 
Peters G, Lingras P, Slezak D (2012) Rough sets selected methods and applications in management and engineering. Springer. https:// doi.org/10.1007/978-1-4471-2760-4

Polkowski L (2002) Advance in soft computing: rough sets mathematical foundations. Physical-Verlag A Springer-Verlag Company

Postavaru O, Anton SR, Toma A (2021) COVID-19 pandemic and chaos theory. Math Comput Simul 181:138-149. https://doi.org/ 10.1016/j.matcom.2020.09.029

Singh N, Adlakha N (2019) A mathematical model for interdependent calcium and inositol 1,4,5-trisphosphate in cardiac myocyte. Netw Model Anal Health Inform Bioinform. https://doi.org/10.1007/ s13721-019-0198-0

Sinha AK, Namdev N (2020a) Feature selection and pattern recognition for different types of skin disease in human body using the rough set method. Netw Model Anal Health Inform Bioinform. https:// doi.org/10.1007/s13721-020-00232-z

Sinha AK, Namdev N (2020b) Computational approach of tumor growth in human body with a significant technique the rough set. IOP Mater Sci Eng 798:012038. https://doi.org/10.1088/1757899X/798/1/012038

Sinha AK, Namdev N (2021a) A mathematical model of tumor growth in human body with the rough set. Sci Technol Asia 26:30-38. https://doi.org/10.14456/scitechasia.2021.4

Sinha AK, Namdev N, Kumar A (2018) Rough set method accurately predicts unknown protein class/family of leishmania donovani membrane proteome. Math Biosci 301:37-49. https://doi.org/10. 1016/j.mbs.2018.03.027

Sinha AK, Namdev N, Kumar A (2020) A mathematical model of adiponectin resistance. J Theor Biol. https://doi.org/10.1016/j. jtbi.2020.110246

Sinha AK, Namdev N (2020) Mathematical modeling of lung cancer using rough sets. Internat J Adv Res Eng Technol 11:1-10. https:// ssrn.com/abstract $=3565100$

Sinha AK, Namdev N (2021) The analysis of the outbreak of COVID19 in a regional context. High Technol Lett 27: 27. http://www. gjstx-e.cn/gallery/27-april2021.pdf

Skowron A (2005) RSES 2.2 user's guide (2005) Warsaw University. https://www.mimuw.edu.pl/ szczuka/rses/RSES_doc_eng.pdf

The Week (2020) https://www.theweek.in/news/health/2020/07/10/mitstudy-predicts-2-lakh-covid-19-cases-per-day-in-india-by-2021end-whycontroversial.html?fbclid=IwAR2yi7qKX2ZuRkof6b 6Nc4Hk9_FTqD45F_SGr4htb50Vh6bjqoE4zBtJ6so

Tiirinki H, Tynkkynen LK, Sovala M, Atkins S, Koivusalo M, Rautiainen P, Jormanainen V, Keskimäki I (2020) COVID-19 pandemic in Finland - Preliminary analysis on health system response and economic consequences. Health Policy Technol 9:649-662. https://doi.org/10.1016/j.hlpt.2020.08.005

Tuite AR, Fisman DN (2020) Reporting, epidemic growth, and reproduction numbers for the 2019 novel Coronavirus (2019-nCoV) epidemic. Ann Intern Med. https://doi.org/10.7326/M20-0358
Wu Z, McGoogan JM (2020) Characteristics of and important lessons from the Coronavirusdisease 2019 (COVID-19) outbreak in China: summary of a report of 72,314 casesfrom the Chinese center for disease control and prevention. JAMA 323:1239-1242. https://doi.org/10.1001/jama.2020.2648

Wu P, Hao X, Lau EHY, Wong JY, Leung KSM, Wu JT et al (2020b) Real-time tentativeassessment of the epidemiological characteristics of novel coronavirusinfections in Wuhan, China, as at 22 January 2020. Eurosurveillance 25:2000044. https://doi.org/10. 2807/1560-7917.ES.2020.25.3.2000044

Wu JT, Leung K, Leung GM (2020) Nowcasting and forecasting the potential domestic andinternational spread of the 2019-nCoV outbreak originating in Wuhan, China: a modelling study. Lancet (2020). http://www.sciencedirect.com/science/article/pii/S1201 971220300539.

Xu W, Wu J, Cao L (2020) COVID-19 pandemic in China: context, experience and lessons. Health Policy Technol 9:639-648. https:// doi.org/10.1016/j.hlpt.2020.08.006

Yousefpour A, Jahanshahi H, Bekiros S (2020) Optimal policies for control of the novel coronavirus disease (COVID-19) outbreak. Chaos Solitons Fractals 136:109883. https://doi.org/10.1016/j. chaos.2020.109883

Zhao S, Gao D, Zhuang Z, Chong M, Cai Y, Ran J et al (2020c) Estimating the serial interval of the novel coronavirus disease (COVID-19): a statistical analysis using the public data in Hong Kong. medRxiv. https://doi.org/10.1101/2020.02.21.20026559

Zhao S, Musa SS, Lin Q, Ran J, Yang G, Wang W, et al. (2020) Estimating the unreported number of novel Coronavirus (2019-nCoV) cases in China in the first half of January 2020: a data-driven modelling analysis of the early outbreak. J Clin Med 9. https:// www.mdpi.com/2077-0383/9/2/388

Zhao S, Lin Q, Ran J, Musa SS, Yang G, Wang W, et al. (2020) Preliminary estimation of the basic reproduction number of novel coronavirus (2019-nCoV) in China, from2019 to 2020: a datadriven analysis in the early phase of the outbreak. International J Infect Dis 92:214-217. http://www.sciencedirect.com/science/ article/pii/S1201971220300539.

Zhou P, Yang XL, Wang XQ, Hu B, Zhang L, Zhang W, Si HR, Zhu Y, Li B, Huang CL, Chen J, Luo Y, Guo H, Jiang RD, Liu MQ, Chen Y, Shen XR, Wang X, Zheng XS, Zhao K, Chen QJ, Dong F, Liu LL, Yon B, Zhan FX, Wang YY, Xiao GF, Shi ZL (2020) A pneumonia outbreak associated with a new coronavirus of probable bat origin. Nature 579:270-273. https://doi.org/10.1038/ s41586-020-2012-7

Publisher's Note Springer Nature remains neutral with regard to jurisdictional claims in published maps and institutional affiliations. 